\title{
MEDIDAS DE NASALÂNCIA DA FALA DE CRIANÇAS COM FISSURA LÁBIO-PALATINA E SUA CORRELAÇÃO COM O JULGAMENTO PERCEPTIVO-AUDITIVO DA NASALIDADE
}

\section{Luciana Silva}

Dissertação apresentada à Faculdade de Odontologia de Bauru, da Universidade de São Paulo, como parte dos requisitos para obtenção do título de Mestre em Fonoaudiologia. 


\title{
MEDIDAS DE NASALÂNCIA DA FALA DE CRIANÇAS COM FISSURA LÁBIO-PALATINA E SUA CORRELAÇÃO COM O JULGAMENTO PERCEPTIVO-AUDITIVO DA NASALIDADE
}

\section{Luciana Silva}

\begin{abstract}
Dissertação apresentada à Faculdade de Odontologia de Bauru, da Universidade de São Paulo, como parte dos requisitos para obtenção do título de Mestre em Fonoaudiologia.
\end{abstract}

Orientadora: Prof. Dra. Maria Inês Pegoraro-Krook 
Silva, Luciana

Si38m Medidas de nasalância da fala de crianças com fissura lábio-palatina e sua correlação com o julgamento perceptivoauditivo da nasalidade./ Luciana Silva. - Bauru, 2007. 91p. il., $30 \mathrm{~cm}$.

Dissertação (Mestrado) -- Faculdade de Odontologia de Bauru. Universidade de São Paulo.

Orientadora: Prof. Dra Maria Inês Pegoraro-Krook

Autorizo, exclusivamente para fins acadêmicos e científicos, a reprodução total ou parcial desta dissertação.

Assinatura:

Data: 


\section{DADOS CURRICULARES}

\section{LUCIANA SILVA}

26 de Agosto de 1979

Nascimento / Divinópolis-MG

$1999-2002$

Graduação em FonoaudiologiaUniversidade de Franca / Unifran $-\mathrm{SP}$.

$2003-2004$

Curso de Especialização na área de Linguagem, pela Faculdade de Odontologia de Bauru, da Universidade de São Paulo, Bauru $-\mathrm{SP}$.

$2004-2005$

Curso de Aprimoramento em Fonoaudiologia aplicado a Odontologia - Faculdade de Odontologia de Bauru, da Universidade de São Paulo, Bauru $-\mathrm{SP}$.

Mestrado em Fonoaudiologia, na $2005-2007$ Faculdade de Odontologia de Bauru da Universidade de São Paulo, Bauru - SP. 
"Deixe cada um tornar-se tudo o que for capaz de ser

Expandir-se, se possível, até seu florescimento.

Suportar todas as limitações, rejeitar tudo o que for estranho,

Especialmente os aspectos nocivos.

E mostrar-se em toda a grandeza de sua dimensão e estatura. SER AQUILO QUE PUDER!"

Karl König 


\section{DEDICATÓRIA}

Dedico este trabalho e todo o meu mestrado a minha mãe. Uma mulher que "Ousou ser feliz e foi"... Que sempre me incentivou a buscar o "melhor" para ser feliz, seguindo meu coração. E mesmo nos seus últimos momentos de lucidez, ainda me encorajou a conquistar o que ela não havia conseguido.

"Mã Quelida", só não desisti por você! Sempre que pensava em desistir, me lembrava das suas últimas palavras e insistia neste "nosso" sonho. Como foi difícil separar as coisas! Sentir-me realizada, e seguir meu caminho sem você! Que saudade enorme! Como eu queria tê-la ao meu lado para dividir cada angústia, cada alegria que vivi nestes dois anos.

Mesmo diante das adversidades, cheguei ao fim. Espero que aí no céu, você esteja feliz com mais esta "nossa" conquista.

"I love you!"

Saudades... 


\section{AGRADECIMENTOS ESPECIAIS}

Agradeço inicialmente ao meu Pai. Um homem sempre exemplar. Sem ele eu não poderia estar aqui, tão pouco concluir este mestrado.

Ao meu irmão, pela força e carinho. Carlos, também lhe peço desculpas pela minha ausência nos seus momentos mais difíceis, quando precisou muito de mim e não me encontrou, pois, em função das minhas escolhas, não pude fazer tudo.

À Julia, minha sobrinha tão linda! Que também fui ausente, deixando de acompanhar seus primeiros momentos. Mas prometo que recuperaremos todo este tempo em que não estivemos juntas!

Ao Francisco, pelo amor, carinho e paciência! Pode ter certeza que vai valer à pena! 


\section{AGRADECIMENTOS}

À Prof ${ }^{\mathrm{a}}$ Dr $^{\mathrm{a}}$ Maria Inês Pegoraro-Krook, coordenadora do Programa de Pós-graduação em Fonoaudiologia do Departamento de Fonoaudiologia da FOB - USP e orientadora deste trabalho, sou grata e me sinto privilegiada em ser sua orientanda.

À Dr$^{\mathrm{a}}$ Jeniffer De Cássia Rillo Dutka Souza. Nunca saberei como te agradecer por tudo que fez por mim! Sem você esta dissertação não seria a mesma. Como aprendi com você! Mestre, amiga, companheira... Tudo que aprendi neste último ano, devo a você. Obrigada pela paciência, carinho e dedicação!

À professora Luciana Paula Maximino De-Vitto. Obrigada pelas palavras de carinho, apoio, por acreditar em mim e me incentivar sempre. Você é uma das grandes responsáveis pela minha paixão pela linguagem e um exemplo de professora que quero seguir sempre.

A equipe do projeto Flórida. Sempre todos dispostos a ajudar, em especial a Teresa e a Andréa: obrigada. pelo apoio nos meus momentos mais difíceis. E aos que me ajudaram diretamente na realização do trabalho: Douglas, Robert e Rita. O que seria de mim, sem vocês? 
Às meninas da Fonética, Simone, lara e Janaína: nossas "terapias em grupo" foram ótimas!

À Olívia, que mesmo chegando neste final, tem sempre uma palavra otimista. Espero que sejamos amigas por muito tempo.

À Tia Maria Helena, pelas correções de português. Sempre disposta a ajudar! Muito obrigada.

Enfim, a todos que me apoiaram e me incentivaram com palavras amigas, que estiveram sempre ao lado.

Obrigada. 
SUMÁRIO

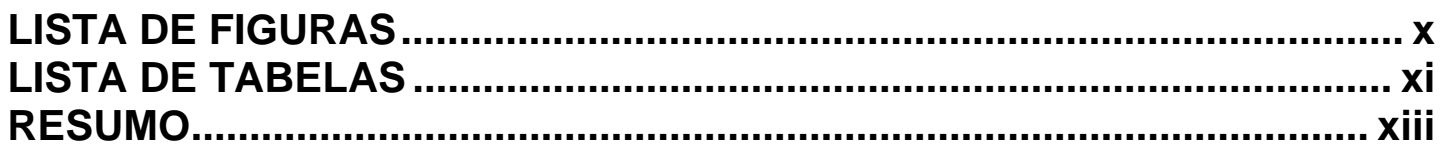

1 INTRODUÇÃO ……............................................................... 1

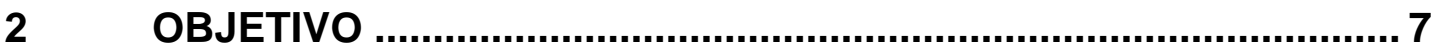

3 REVISÃO DE LITERATURA ..................................................... 11

3.1 Avaliação Perceptivo-Auditiva da Nasalidade ............................... 13

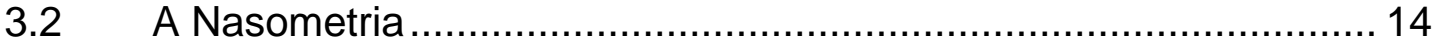

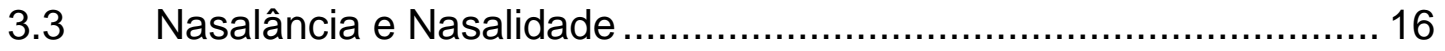

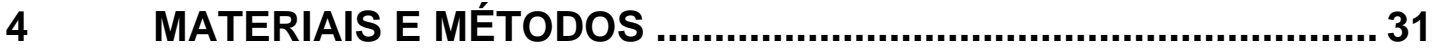

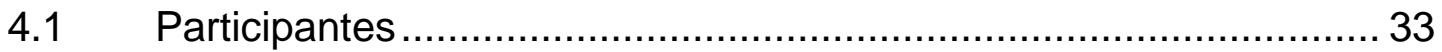

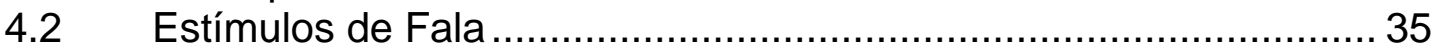

4.3 Procedimentos Para Gravação das Amostras de Fala ..................... 35

4.4 Julgamento Perceptivo-Auditivo das Amostras de Fala.................... 36

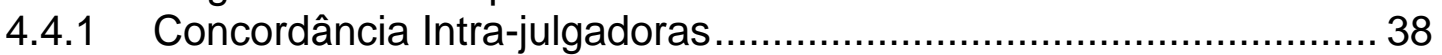

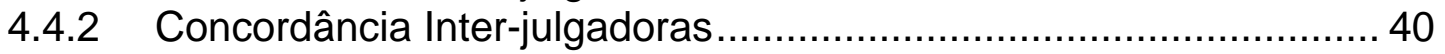

4.4.3 Interpretação dos Julgamentos Perceptivo-Auditivos ...................... 43

4.5 Procedimentos para Captação, Armazenamento e Cálculo dos Dados da Nasometria ........................................................ 44

4.5.1 Escore de Nasalância.................................................................... 47

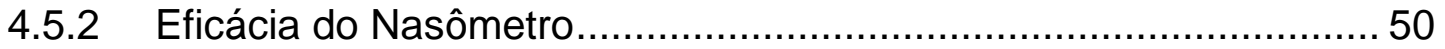

4.6 Análise Estatística dos Dados ................................................ 52

$5 \quad$ RESULTADOS

5.1 Julgamento Perceptivo-Auditivo ……………........................... 57

5.2 Índices de Eficiência da Nasometria.............................................. 58

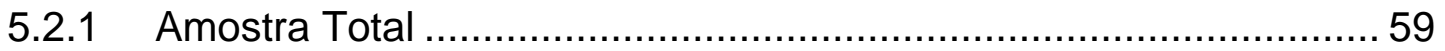

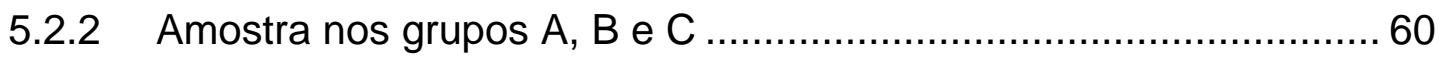

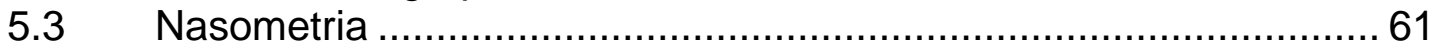

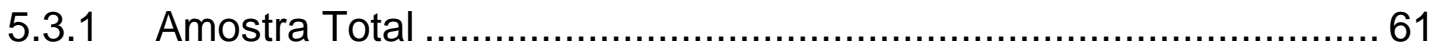

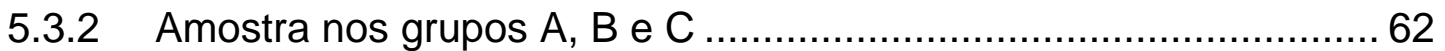

5.4 Correlação entre nasalância e nasalidade de fala............................ 63

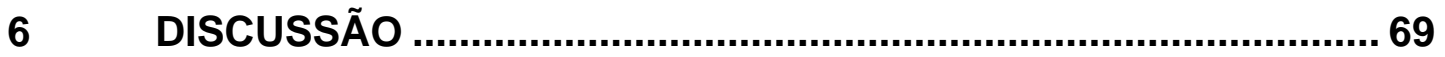

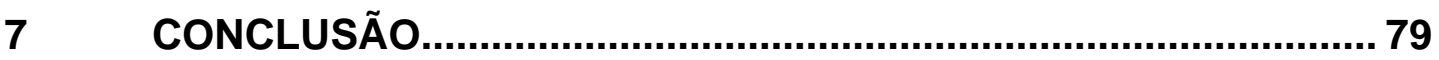

REFERÊNCIAS

ABSTRACT 


\section{LISTA DE FIGURAS}

Figura 1 - Computador para as gravações e análise das amostras de audio das emissões (a), computador para as gravações e análise das nasometrias (b), e placa separadora de som com os microfones segundo adaptação de Dutka (1992)

Figura 2 - Gráfico apresentado na tela no computador a partir do software de análise do Nasômetro 6200-2 (Kay Elemetrics Corp.), onde "1" representa a emissão de /pa pa pa/ e "2" representa a emissão de /ma ma ma/ (Figura adaptada de Lima, 2006, com permissão) 48

Figura 3 - Tela do computador gerada a partir do software de análise do Nasômetro 6200-2 (Kay Elemetrics Corp.) ilustrando o valor médio de nasalância de $17,66 \%$ identificado pela SETA "A" obtido para a amostra de fala composta apenas fonemas orais selecionada pelos cursores identificados pela SETA "B" (figura adaptada de Lima, 2006, com permissão). 49

Figura 4 - Tela do computador gerada a partir software de análise do Nasômetro 6200-3 (Kay Elemetrics Corp.), ilustrando o valor médio de nasalância de $75,15 \%$ identificado pela SETA " $A$ " obtido para a amostra de fala contendo apenas fonemas nasais selecionada pelos cursores identificados pela SETA "B" (figura adaptada de Lima, 2006, com permissão). 49 


\section{LISTA DE TABELAS}

Tabela 1 - Estudos que investigaram relação entre nasalância e julgamentos perceptivo-auditivos da nasalidade.

Tabela 2 - Valores expressos em porcentagem quanto à concordância intrajulgadoras de acordo com o julgamento perceptivo-auditvo

Tabela 3 - Valores expressos em porcentagem quanto à concordância interjulgadoras de acordo com o julgamento perceptivo-auditvo.

Tabela 4 - Cálculo dos índices de sensibilidade e de especificidade do nasômetro na identificação da hipernasalidade.

Tabela 5 - Médias dos julgamentos perceptivo-auditivos por julgadoras e média do julgamento perceptivo auditivo do prontuário. .58

Tabela 6 - Resultados dos índices de sensibilidade e de especificidade do nasômetro para as duas palavras e frases 59

Tabela 7 - Resultados dos índices de sensibilidade e de especificidade do nasômetro na identificação da hipernasalidade para a amostra de fala separada conforme os grupos A, B e C 61

Tabela 8 - Médias e desvios padrão de nasalância expressos em porcentagem obtidos para os indivíduos da amostra durante a emissão das palavras e frases.

Tabela 9 - Correlações ("r") entre julgamento perceptivo da nasalidade realizado pelas três julgadoras para as frases e palavras e medidas de nasalância para os 79 indivíduos para as mesmas frases e palavras. Também apresenta correlações ("r") entre julgamento perceptivo coletado do prontuário 
e medidas de nasalância obtidas para emissão das palavras e

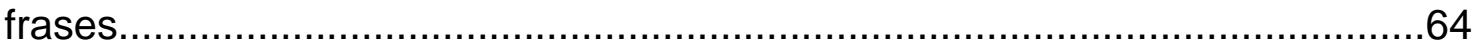

Tabela 10 - Correlações ("r") entre julgamento perceptivo auditivo da nasalidade em normal e hipernasal e medidas de nasalância obtidas para as palavras e frases para o grupo A 65

Tabela 11 - Correlações ("r") entre julgamento perceptivo auditivo da nasalidade em normal e hipernasal e medidas de nasalância obtidas para as palavras e frases para o grupo $B$ 66

Tabela 12 - Correlações ("r") entre julgamento perceptivo auditivo da nasalidade em normal e hipernasal e medidas de nasalância obtidas para as palavras e frases para o grupo C. 67 
RESUMO 


\section{RESUMO}

Este estudo teve como objetivo correlacionar medidas de nasalância e nasalidade da fala de 79 crianças de ambos os sexos, com idades entre 4 e 9 anos (média 6,5 anos), falantes do Português brasileiro, com fissura unilateral de lábio e palato operada, operadas do palato entre 12 e 18 meses de idade. Todas as crianças já apresentavam avaliação perceptivo-auditiva da nasalidade, avaliação nasométrica e gravação de áudio realizadas previamente realizadas no (HRAC-USP). Das gravações de áudio pré-existentes foram selecionadas para este estudo as palavras: "papai" e "bebê", e as sentenças "Papai pediu pipoca" e o "O bebê babou". Apesar de já existir no prontuário de cada criança uma avaliação perceptivo-auditiva indicando que as mesmas apresentavam hipernasalidade em grau leve, moderado ou severo, as amostras deste estudo, gravadas simultaneamente à nasometria, foram novamente julgadas por três fonoaudiólogas experientes. Para o julgamento perceptivo as fonoaudiólogas deveriam classificar a nasalidade por meio de uma escala de 4 pontos ( 1 = nasalidade normal, $2=$ hipernasalidade leve, $3=$ hipernasalidade moderada e 4 = hipernasalidade severa). Os valores atribuídos aos julgamentos obtidos pelas três fonoaudiólogas variaram de 1,0 a 3,3, tanto para as palavras como para as sentenças. Considerando o valor de corte de 1,5 para o julgamento perceptivo da nasalidade, 50 (63\%) das crianças tiveram médias iguais ou abaixo de 1,5 e 29 (37\%) tiveram médias acima deste valor, para o julgamento da palavra "papai". Para "bebê", 46 (58\%) tiveram médias iguais ou abaixo de 1,5 e 33 (42\%) médias acima deste valor. Para a frase "Papai pediu pipoca" 42 (53\%) tiveram médias iguais ou abaixo de 1,5 e 37 (47\%) tiveram médias acima deste valor. Para a frase "O bebê babou" 43 (54\%) dos indivíduos tiveram médias iguais ou abaixo de 1,5 e 36 (46\%) médias acima deste valor. Os resultados ainda evidenciaram uma sensibilidade de $44 \%$ do nasômetro em identificar hipernasalidade para a palavra "papai", de 23\% para a palavra "bebê", de $45 \%$ para a frase "Papai pediu pipoca" e de $30 \%$ para a frase o "O bebê babou". Quanto à especificidade, foram encontrados os resultados de 70\% para "papai", 93\% para "bebê", 81\% para "Papai pediu pipoca" e 92\% para "O bebê babou". Os valores médios de nasalância obtidos neste estudo foram: 24\% para a palavra "papai", 39\% para bebê, 32\% para "Papai pediu pipoca" e 39\% para "O bebê babou". Concluímos com nosso estudo que a correlação entre nasalância e nasalidade em uma amostra de crianças com ressonância de fala variando entre normal e hipernasal leve é baixa, principalmente quando se utiliza estímulos de fala curtos com predomínio de uma única consoante. Sugerimos que estudos futuros que tenham como objetivo correlacionar nasalância e nasalidade utilizem estímulos de fala mais longos, com diferentes contextos fonéticos. Além disso, o controle de variáveis que possam influenciar no julgamento perceptivo auditivo da nasalidade como ronco nasal, emissão de ar nasal, presença de articulações compensatórias deveriam ser consideradas. Sugerimos ainda, que o valor de corte seja estabelecido para cada amostra de indivíduos, pois o que pode ser bom para uma amostra, pode não ser bom para outra.

Palavras-chave: fissura lábio-palatina, nasometria, julgamento perceptivoauditivo, hipernasalidade, ressonância de fala. 
1 INTRODUÇÃO 



\section{INTRODUÇÃO}

A fala é a principal forma de comunicação humana, que envolve a produção de sons articulados com significado, e tem o papel de transmitir as intenções do interlocutor. Esta habilidade necessita de um adequado funcionamento do sistema nervoso, auditivo, respiratório, da laringe, das cavidades supraglóticas e dos órgãos fonoarticulatórios (palato duro e mole, mandíbula e língua, lábios e dentes. (KENT, 1996).

Para que ocorra a produção normal de sons orais da fala é necessária a separação da cavidade oral da nasal. (KUMMER 2001, PERTERSON-FALZONE et al., 2001, BZOCH, 2004). Ou seja, se não houver comunicação entre estas cavidades durante a produção de sons orais, percebe-se uma ressonância normal de fala. No entanto, quando por algum motivo existe comunicação entre as cavidades oral e nasal durante a produção de sons orais, ondas acústicas adentram a cavidade nasal indesejavelmente levando à hipernasalidade da fala. (BAKEN, 1997).

A fissura de palato (FP) e a disfunção velofaríngea (DVF) são condições que resultam numa comunicação indesejada entre as cavidades nasal e oral durante a produção da fala oral. A fissura labiopalatina é uma das anomalias congênitas mais comuns, podendo ocorrer com uma freqüência mundial de 1:700 nascimentos. (MURRAY, 2002). Esta malformação ocorre devido à falta de fusão dos processos embrionários responsáveis pela formação da face (um frontonasal, dois mandibulares e dois maxilares) que 
formam o lábio entre a $4^{a}$ e $6^{a}$ semana de vida intra-uterina e o palato entre a $10^{\mathrm{a}}$ e a $12^{\mathrm{a}}$ semana.

A DVF é qualquer alteração do funcionamento do mecanismo velofaríngeo (MVF) que pode ser resultante da falta de tecido do palato mole para se alcançar o fechamento velofaríngeo (insuficiência velofaríngea), da falta de competência neuromuscular no movimento das estruturas velofaríngeas (incompetência velofaríngea) e de hábitos articulatórios inadequados e/ou compensatórios aprendidos na infância que se devem a alterações físicas ou neuromusculares do MVF. (TROST-CARDAMONE, 2004). Dentre as alterações de fala que a criança com FP ou DVF pode ter, a hipernasalidade é uma das características mais marcantes.

A hipernasalidade é a ressonância excessiva na cavidade nasal durante a produção de fala oral, quando deveria haver um equilíbrio oro-nasal. Esta ressonância excessiva ocorre devido ao acoplamento das cavidades oral e nasal, durante a emissão dos sons orais, decorrente principalmente da disfunção do MVF após a correção primária da fissura de palato. (BZOCH, 2004).

Tradicionalmente, a ressonância de fala é avaliada pelo fonoaudiólogo, por meio de uma avaliação perceptivo-auditiva. Embora muitos fonoaudiólogos concordem que julgamentos subjetivos são o meio mais básico e mais importante para a identificação do distúrbio de ressonância, (MOON, 
1993, KENT, 1996, DUTKA, 1996) ainda há muitas controvérsias sobre a utilização desta forma de avaliação como o único meio para avaliar a ressonância de fala, visto que a concordância entre os julgamentos intra e/ou interavaliadores pode variar muito e que ainda há uma falta de padronização dos testes usados pelos avaliadores. (PEGORARO-KROOK, 2004).

O uso de medidas instrumentais objetivas, padronizadas e normatizadas para avaliar a função velofaríngea tem sido recomendado com freqüência na literatura, com o intuito de auxiliar e complementar a avaliação clínica. (DALSTON, 1991, MOON, 1993). Por este motivo, a análise instrumental acústica do sinal de fala foi desenvolvida como meio de corroborar os testes perceptivos da ressonância de fala. Mais especificamente, o nasômetro foi desenvolvido originalmente para fornecer medidas objetivas da nasalidade de fala. (FLETCHER et al., 1989). Este instrumento fornece um quociente indicativo da porcentagem da energia acústica nasal sobre a energia acústica nasal mais a energia acústica oral presente na fala do indivíduo (nasalância) e não envolve riscos ao paciente, nem é física ou psicologicamente invasivo.

A validade do nasômetro para medir hipernasalidade tem sido demonstrada por inúmeros pesquisadores, resultando na aceitação e na utilização da nasometria tanto na clínica como na pesquisa. Vários estudos têm demonstrado a relação entre nasalância (medida acústica fornecida pelo nasômetro) e o julgamento perceptivo auditivo da hipernasalidade. (DALSTON, 1991, HARDIN et al., 1992, NELLIS et al., 1992, DALSTON, SEAVER, 1992, 
WATTERSON et al., 1996, 1998, KEUNING et al., 2002, VAN LIERD et al., 2002, LEWIS et al., 2003, HIRSCHBERG et al., 2006).

Em particular no Português Brasileiro alguns estudos foram realizados com o objetivo de normatizar os valores de nasalância. (SUGUIMOTO; PEGORARO-KROOK, 1995, TRINDADE et al., 1997, RIBEIRO, 1999, DI NINNO et al., 2001). Apesar de contribuírem para o desenvolvimento de um banco de dados da nasalância no Português Brasileiro nenhum destes estudos verificou a correlação entre os dados de nasalância e os achados perceptivo-auditivos para as populações estudadas. Informações quanto à correlação entre nasalância e nasalidade são importantes para a validação do uso do instrumento em falantes do Português Brasileiro. 
2 OBJETIVO 



\section{OBJETIVO}

O objetivo deste estudo foi o de estabelecer a correlação entre medidas de nasalância e o julgamento perceptivo-auditivo da nasalidade em uma amostra de fala do Português Brasileiro. 

3 REVISÃO DE LITERATURA 



\section{REVISÃO DE LITERATURA}

O objeto de estudo deste trabalho é a nasalidade de fala a qual, segundo BAKEN (1997), se refere a uma qualidade de fala inaceitável que resulta do acoplamento das cavidades oral e nasal/nasofaringe durante produção de sons orais fala. Para diagnosticar e tratar a hipernasalidade, o fonoaudiólogo faz uso da percepção-auditiva sendo por meio desta percepção que o profissional identifica a presença da ressonância excessiva na cavidade nasal durante a produção de fonemas que envolvem a vibração das pregas vocais, como as vogais e as consoantes vozeadas. (BZOCH, 2004, KUMMER, 2001, PERTERSON-FALZONE et al., 2001; 2006).

\subsection{Avaliação perceptivo-auditiva da nasalidade}

São vários os autores que propõem o uso de protocolos específicos para a avaliação da nasalidade de fala. (PEGORARO-KROOK, 1995; TRINDADE; TRINDADE JR., 1996, KUMMER, 2001, PETERSON-FALZONE et al., 2001, BZOCH, 2004, GENARO et al., 2004). Com base em julgamentos perceptivo-auditivos, clínicos podem identificar e caracterizar tanto a presença quanto o grau da nasalidade de fala. (GENARO et al., 2004). As medidas perceptivas descritas na literatura para classificar subjetivamente o distúrbio de nasalidade (hiper ou hiponasalidade) se baseiam na grande maioria em classificações baseadas em comparações pareadas (nasalidade normal e presença ou ausência de hiper ou hiponasalidade), e em escalas numéricas para indicação do grau da severidade do distúrbio $(1$ = nasalidade normal, 2 = 
hiper ou hiponasalidade leve, 3 = hiper ou hiponasalidade moderada, $4=$ hiper ou hiponasalidade severa, por exemplo), conforme descreve. (PEGORAROKROOK, 2004).

Apesar da reconhecida importância dos julgamentos perceptivoauditivos, tanto pesquisadores quanto clínicos afirmam que são muitas as limitações associadas ao uso desta forma de avaliação subjetiva. (KENT, 1996, KUMMER, 2001, PETERSON-FALZONE et al., 2001, BZOCH, 2004). A grande variação nos níveis de concordância entre os julgamentos intra e/ou interavaliadores, por exemplo, é uma importante limitação no uso isolado da avaliação perceptivo-auditiva. (KENT, 1996).

A análise instrumental do sinal de fala, portanto, foi desenvolvida para complementar os testes perceptivo-auditivos, uma vez que possibilita uma análise mais objetiva e quantitativa de vários aspectos da fala. Dentre os vários tipos de avaliação instrumental do sinal de fala encontra-se a nasometria, técnica de interesse neste estudo.

\subsection{Nasometria}

FLETCHER, em 1970, criou o primeiro instrumento capaz de medir a razão entre a energia acústica oral e nasal chamado de TONAR (The OralNasal Acoustic Ratio). Seis anos mais tarde, FLETCHER (1976) aprimorou o instrumento para o TONAR II, introduzindo no sistema uma equação para 
classificar a porcentagem de "nasalância". Na fórmula, nasalância é a razão numérica do nível de pressão sonora (NPS) nasal sobre a soma do (NPS) oral mais o (NPS) nasal, multiplicada por 100. (FLETCHER, 1978).

A empresa Kay Elemetrics Corp, em 1987, inseriu no mercado um instrumento com princípio semelhante ao do TONAR II, o nasômetro. O instrumento é operado por meio de um microcomputador, no qual os níveis de pressão sonora oral e nasal do sinal acústico da fala são captados por dois microfones posicionados em uma placa horizontal de metal a qual permite a captação das ondas sonoras simultaneamente por um microfone direcionado à boca e por outro direcionado ao nariz do indivíduo. O sinal de cada um dos microfones é filtrado e digitalizado por módulos eletrônicos num processador e analisado por um software específico para a nasometria, o qual permite o cálculo do grau de nasalância.

O valor de nasalância, portanto, reflete a quantidade relativa da energia acústica nasal da fala de um indivíduo, fornecendo um correlato acústico da nasalidade de fala. Isto é, nasalidade e nasalância não são sinônimos e têm uma relação semelhante à relação entre pitch e freqüência fundamental ou entre loudness e intensidade de fala. Isto é, enquanto a nasalidade se refere ao aspecto percebido pelo ouvinte (aspecto este rico em vários parâmetros subjetivos) a nasalância fornece um parâmetro acústico da nasalidade o qual se baseia num único aspecto físico da fala: o nível de pressão sonora. 
O nasômetro tem sido usado com freqüência por profissionais que atuam na área craniofacial investigando vários aspectos como idade (ROCHET et al., 1998, VAN LIERDE et al., 2003), gênero (DI NINNO et al., 2001, VAN LIERDE et al., 2001), dialeto (HIRSCHBERG et al., 2006, SWENNEN et al., 2004), amostras de fala (WATTERSON, 1999) e também por muitos pesquisadores interessados em estudar a relação entre nasalidade e nasalância (DALSTON et al.,1991, HARDIN et al., 1992, NELLIS et al., 1992, DALSTON; SEAVER 1992, DALSTON et al., 1993, DUTKA 1996, WATTERSON et al., 1996, 1998, KEUNING et al., 2002, LEWIS, 2003 e HIRSCHBERG. et al., 2006). De um modo geral, estes autores constataram que a correspondência entre a nasometria e o julgamento perceptivo-auditivo não é exata, embora a nasometria tenha sido efetiva na detecção de pacientes que tiveram parecer clínico, de hipernasalidade importante.

\subsection{Nasalância e nasalidade}

DUTKA (1996) descreveu que tanto a análise da correlação quanto à estimativa da eficácia do nasômetro são formas de estudarmos a relação entre nasalância e nasalidade. Vários estudos analisaram esta correlação, sendo que alguns autores encontraram alta correlação (DALSTON; SEAVER 1992; DALSTON et al., 1993, DUTKA, 1996, WATTERSON, 1998, HIRSCHBERG et al., 2006), outros encontraram moderada correlação (WATTERSON et al., 1996, KEUNING et al., 2002, LEWIS et al., 2003), e outros encontraram baixa correlação (NELLIS et al., 1992). Vide Tabela 1. Alguns estudos analisaram a 
eficácia do nasômetro. (DALSTON et al., 1991; HARDIN et al., 1992, WATTERSON et al., 1993, DALSTON et al., 1993, WATTERSON et aL., 1996).

DALSTON et al. (1991) verificaram a correspondência entre nasalância, estimativas aerodinâmicas da área velofaríngea acima de $10 \mathrm{~cm}^{2} \mathrm{e}$ os julgamentos clínicos de hipernasalidade em 117 pacientes com idades entre 5 e 56 anos (média de 17 anos). Os dados do nasômetro foram obtidos enquanto os pacientes liam ou repetiam um texto padronizado sem consoantes nasais. A avaliação perceptiva da hipernasalidade de fala foi realizada durante a fala espontânea por um avaliador experiente, usando uma escala de 6 pontos (variando de $1=$ normal a $6=$ hipernasalidade severa). Utilizando o valor de corte de $32 \%$ de nasalância, a sensibilidade e a especificidade do nasômetro na identificação da presença ou da ausência da área velofaríngea acima de $10 \mathrm{~cm}^{2}$ foi de $78 \%$ e $79 \%$, respectivamente. A sensibilidade e a especificidade do nasômetro na identificação correta dos indivíduos com hipernasalidade de fala foi de $89 \%$ e de $95 \%$ respectivamente, e a eficiência do instrumento em confirmar os achados perceptivo-auditivos foi de $93 \%$. Os autores concluíram que o nasômetro é um instrumento apropriado para uso clínico e pode ser de grande valor na avaliação de indivíduos com alteração na função velofaríngea para fala.

HARDIN et al. (1992) verificaram a relação entre escores de nasalância e julgamentos perceptivos da hiper e da hiponasalidade em 74 indivíduos com idades entre 6 e 52 anos (média da idade e sexo dos falantes não foram indicados pelos autores). Destes 74 indivíduos, 23 eram do grupo 
controle e 51 apresentavam fissura de palato operada, sendo que 29 destes 51 indivíduos também tinham sido submetidos a uma faringoplastia. A nasalância foi obtida durante a leitura de sentenças constituídas exclusivamente por fonemas nasais e de um texto padronizado contendo apenas vogais e consoantes orais (Zoo Passage). A avaliação perceptiva da hiper e da hiponasalidade foi realizada por 3 julgadores usando uma escala de severidade de 7 pontos (variando de $1=$ normal a $7=$ hiper ou hiponasalidade severa). $\mathrm{Na}$ comparação entre julgamento perceptivo e nasalância, os resultados mostraram sensibilidade de $57 \%$, especificidade de $91 \%$ e eficiência de $81 \%$ ao ser usado o valor de corte de $32 \%$ de nasalância. Quando os indivíduos com retalho faríngeo foram excluídos da amostra, a sensibilidade aumentou para $60 \%$, a especificidade para $97 \%$ e a eficiência para $84 \%$. Os autores também compararam os valores de corte de $32 \%$, de $26 \%$ e de $50 \%$ de nasalância, encontrando melhores resultados na utilização do escore de $26 \%$ nos quais foram encontrados os valores de sensibilidade de $76 \%$, especificidade de $85 \%$ e eficiência de $82 \%$. Excluídos os indivíduos com retalho faríngeo e usando o valor de corte de $26 \%$, a sensibilidade encontrada foi de $87 \%$, a especificidade de $93 \%$ e a eficiência de $91 \%$. Os autores concluíram que a eficiência da nasometria foi pior em pacientes com retalho faríngeo.

NELLIS et al. (1992) verificaram a relação entre escores de nasalância e julgamento perceptivo da nasalidade em 16 indivíduos com retalho faríngeo com idades variando entre 8 e 18 anos de idade (média da idade e sexo dos falantes não foram indicados pelos autores). Escores de nasalância foram obtidos após a leitura de 7 sentenças: 4 constituídas apenas 
por fonemas orais e 3 por fonemas orais e nasais (oro-nasais). A avaliação perceptivo-auditiva da hiper e da hiponasalidade foi realizada por 10 estudantes de fonoaudiologia que utilizaram duas escalas de 6 pontos (variando de $1=$ normal a $6=$ hiper ou hiponasalidade severa). Os autores reportaram uma correlação significante entre os escores de nasalância e a percepção da hiponasalidade apenas para 3 sentenças oro-nasais $(-0,65$; $0,54 ;-0,62)$, isto é, aumentos dos escores de nasalância foram associados a uma redução sistemática na percepção da hiponasalidade apenas durante a produção de algumas sentenças nasais. Já os valores de correlação encontrados entre os escores de nasalância e a percepção da hipernasalidade durante a produção das 4 sentenças orais e das 3 oro-nasais não foram significantes. Os autores reportaram que tanto os escores de nasalância quanto os achados perceptivos indicativos de hiper e de hiponasalidade variaram segundo o contexto fonético das amostras. Algumas limitações foram indicadas pelos autores deste estudo, como por exemplo, o tamanho pequeno da amostra e a ausência de um grupo controle envolvendo indivíduos sem alterações de fala permitindo análise do efeito do contexto fonético na ausência de patologia.

DALSTON; SEAVER (1992) compararam escores de nasalância (obtidos por meio da nasometria) com julgamentos clínicos de hiper e de hiponasalidade (obtidos por meio da avaliação perceptivo-auditiva) e com medidas aerodinâmicas da área nasal total (obtidas por meio de medidas de fluxo-pressão) de 155 pacientes com anomalias orofaciais. Desses indivíduos, 67 eram do sexo feminino e 88 do sexo masculino e as idades variaram entre 3 
e 55 anos (média $=15$ anos). A amostra de fala foi constituída por um texto somente com fonemas orais (texto oral), um texto com fonemas orais e nasais, e uma série de sentenças com fonemas nasais e foi julgada por meio de uma escala de 6 pontos (variando de $1=$ ressonância normal e 6 = hipernasalidade ou hiponasalidade severa). Os autores encontraram correlação significante entre: 1) medidas de nasalância nas sentenças nasais e medidas da área nasal, 2) medidas de nasalância e julgamentos de hiponasalidade, 3) entre medidas de nasalância do texto oral e medidas da área velofaríngea, e 4) entre medidas de nasalância e julgamentos de hipernasalidade. Os autores não encontraram correlação significante entre as medidas de nasalância no texto oral/nasal e área velofaríngea, nem entre área nasal e julgamentos perceptivos de hiper e hiponasalidade.

DALSTON et al. (1993) correlacionaram valores de nasalância com julgamentos clínicos na hipernasalidade da fala de 514 pacientes com fissura de palato, de ambos os sexos, com idades variando entre 3 e 56 anos (média e DP não foram apresentados). Os pacientes eram oriundos de três centros clínicos distintos, sendo dois dos EUA, envolvendo falantes do inglês americano e um da Espanha, envolvendo falantes do espanhol. Os pacientes americanos repetiram ou leram um texto padronizado constituído apenas por fonemas orais (Zoo Passage) e os espanhóis um texto também constituído por fonemas orais (El bosque). O julgamento perceptivo da hipernasalidade foi realizado utilizando-se uma escala de 6 pontos variando de $1=$ ausente, a $6=$ severa) e os escores de nasalância foram obtidos com o nasômetro. Os autores encontraram uma correlação entre nasalidade e nasalância de 0,78. 
Considerando o valor de corte de $29 \%$ para um dos centros americanos os valores de sensibilidade, de especificidade e de eficiência foram de 90\%, 90\% e $90 \%$ respectivamente. Considerando um valor de corte de $25 \%$ para o outro centro americano a sensibilidade encontrada foi de $88 \%$, especificidade de 90\% e a eficiência de $89 \%$. Já para o centro espanhol, considerando o valor de corte de $33 \%$, a sensibilidade foi de $77 \%$, a especificidade de $78 \%$ e a eficiência de $78 \%$. O uso do valor médio dos valores de corte $(28 \%)$ resultou sensibilidade de $87 \%$, especificidade $86 \%$ e eficiência $87 \%$. Os autores concluíram que o nasômetro é útil para confirmar a hipernasalidade observada na clínica.

DUTKA (1996) correlacionou o julgamento perceptivo-auditivo da nasalidade de fala realizado por 10 julgadores com medidas de nasalância. Participaram do estudo 40 indivíduos falantes do Português Brasileiro (25 mulheres e 15 homens), sendo que 27 tinham suspeita de insuficiência velofaríngea e idades entre 4 e 54 anos (média de 18 anos) e 13 tinham fala normal e idades entre 14 e 42 anos (média de 24 anos). As repetições dos estímulos "bebê" e "O bebê babou" foram gravados em áudio simultaneamente à gravação da nasometria. Os 10 julgadores foram treinados brevemente pela autora antes dos julgamentos perceptivo-auditivos das amostras. A correlação entre nasalância e nasalidade foi realizada para todas as amostras (Grupo A), para as amostras que tiveram uma concordância quanto à nasalidade de fala de $70 \%$ ou mais pelos julgadores (Grupo B) e para as amostras com concordância de $85 \%$ ou mais pelos julgadores (Grupo C). Os resultados obtidos evidenciaram uma correlação de 0,73 para a palavra e 0,61 para a 
frase para o grupo A. Uma correlação de 0,80 para a palavra e 0,73 para a frase quanto ao grupo $B$ e para o grupo $C$ uma correlação de 0,81 para a palavra e 0,88 para a frase. Também foi verificada a sensibilidade e especificidade utilizando um valor de corte de $27 \%$ para a palavra e $21 \%$ para a frase. Os resultados mostraram para o grupo A em relação à palavra, sensibilidade de $100 \%$ e especificidade de $40 \%$ e para a frase, sensibilidade de $100 \%$ e especificidade de $29 \%$. Para o grupo B em relação à palavra, a sensibilidade foi de $100 \%$ e a especificidade de $50 \%$, para a frase, a sensibilidade foi de $100 \%$ e a especificidade de $42 \%$. Para o grupo C em relação à palavra, a sensibilidade foi de $100 \%$ e a especificidade de $50 \%$, para a frase a sensibilidade foi de $100 \%$ e a especificidade de $60 \%$. A autora concluiu que o nasômetro é um instrumento eficaz ao corroborar julgamentos de presença ou ausência de hipernasalidade relatada pelos julgadores.

WATTERSON et al. (1996) estudaram a correlação entre julgamentos perceptivo-auditivos de hipernasalidade e nasalância da fala em 40 crianças: 20 sem disfunção velofaríngea (DVF), com idades variando entre 4 e 6 anos e 20 com DVF e idades variando entre 3 e 6 anos, sendo 7 meninas e 13 meninos em cada grupo. No grupo com DVF, 7 haviam realizado cirurgia do lábio e palato, 6 somente do palato e 6 apresentavam DVF sem etiologia conhecida. As crianças de ambos os grupos foram solicitadas a repetir 3 textos: 2 contendo apenas fonemas orais ("Zoo" e "Turtle") e outro contendo fonemas nasais e orais ("Mouse"). $O$ julgamento perceptivo da nasalidade de fala foi realizado por 8 julgadores por meio de uma escala de 5 pontos (variando de 1 $=$ normal a 5 = hipernasalidade severa) e o escore de nasalância foi obtido pelo 
nasômetro. As correlações entre julgamentos perceptivos da hipernasalidade e medidas de nasalância foram estatisticamente significantes para o texto oral "Zôo" ( $r=70 \%)$ e o texto oral "Turtle" $(r=51 \%)$, mas não para o texto misto "Mouse" ( $r=32 \%$ ). Considerando os valores de corte de $22 \%$ para a nasalância e 2,2 para a hipernasalidade, a sensibilidade do nasômetro para confirmar os achados perceptivo-auditivos foi de $72 \%$ para o texto oral "Zôo" e de $83 \%$ para o texto oral "Turtle" (os autores não reportaram a sensibilidade para o texto misto). Não houve diferença estatisticamente significante entre as médias de nasalância para o texto oral "Zôo" e as médias para o texto oral "Turtle", tanto para o grupo sem DVF (15,4\% e 15,7\% respectivamente) quanto para o grupo com suspeita de DVF $(30,4 \%$ e $28,8 \%$, respectivamente). As medidas de nasalância obtidas para os indivíduos com DVF foram significativamente mais altas do que as medidas obtidas para o grupo controle, sem diferenças com relação ao sexo. As medidas de nasalância para o texto "Mouse" também foram significativamente mais altas do que as medidas obtidas para os textos "Zôo" e "Turtle". Os autores concluíram que os valores de correlação encontrados neste estudo foram similares aos valores reportados por outros autores e as diferenças nos escores de nasalância entre os textos orais e o texto misto confirmam a importância de se controlar o conteúdo fonético das amostras.

WATTERSON et al. (1998) compararam os escores de nasalância com a avaliação perceptiva da nasalidade utilizando amostras de fala com fonemas de alta e de baixa pressão, em 25 crianças de 5 a 13, anos sendo 20 pacientes com anomalias craniofaciais e 5 sem história de distúrbios de 
comunicação (os autores não reportaram média de idade ou sexo). A amostra de fala foi composta por 9 sentenças contendo apenas vogais e consoantes de baixa pressão (fonemas líquidos) e por um texto contendo vogais e consoantes de alta pressão (fonemas plosivos e fricativos). A avaliação da nasalidade foi realizada por 7 fonoaudiólogos experientes que julgaram cada amostra utilizando uma escala de 7 pontos (variando entre $0=$ ressonância normal e $6=$ hipernasalidade severa). Para a amostra com fonemas de baixa pressão foi encontrada média de nasalância de $29 \%$ e média do julgamento perceptivoauditivo da nasalidade de 2,3. Para a amostra com fonemas de alta pressão foi encontrada média de nasalância de $30 \%$ e média do julgamento perceptivoauditivo da nasalidade de 2,6. Análises da diferença entre os valores de nasalância e os achados perceptivo-auditivos da nasalidade não foram estatisticamente significantes. Foi encontrada uma correlação entre nasalância e nasalidade de 0,77 para a amostra com consoantes de baixa pressão e de 0,78 para a amostra com consoantes de alta pressão. Considerando o valor de corte de $26 \%$ de nasalância os autores reportaram uma sensibilidade de $84 \%$ e uma especificidade de $88 \%$ do nasômetro ao confirmar a presença e a ausência da hipernasalidade, respectivamente. Os autores concluíram que escores de nasalância e julgamento perceptivo-auditivo da nasalidade confiáveis podem ser obtidos tanto com amostras contendo fonemas de alta pressão quanto de baixa pressão.

WATTERSON et al. (1999) correlacionaram valores de nasalância obtidos durante a produção de amostras de fala curtas envolvendo palavras e frases (com 2, 6 e 17 sílabas) com valores de nasalância obtidos durante a 
produção de um texto com 44 sílabas, todas as amostras contendo apenas fonemas orais,consoantes de baixa pressão e vogais. O contexto fonético de todas as amostras foi oral e envolveu somente consoantes de baixa pressão e vogais. Participaram deste estudo 25 crianças e adolescentes, sendo 20 com DVF e 5 sem DVF e com ressonância normal, com idades entre 5 anos e 14 anos, (média $=7$ anos e 9 meses). Os resultados mostraram uma correlação de 0,95 entre o texto e a frase com 17 sílabas, de 0,93 entre o texto e a frase com 6 sílabas, e de 0,85 entre o texto e a palavra de 2 sílabas. Os autores concluíram que escores de nasalância obtidos durante a produção de frases de 6 e de 17 sílabas foram representativos das amostras de 44 sílabas sugerindo que durante a nasometria o texto pode ser substituído por frases curtas. Concluíram também que a correlação para a palavra foi muito mais baixa do que a correlação obtida para as amostras com as frases, sugerindo que os escores de nasalância não devem ser obtidos durante a produção de uma palavra isolada.

KEUNING et al. (2002) correlacionaram os escores de nasalância com os achados do julgamento perceptivo-auditivo da nasalidade de fala de 43 indivíduos com DVF, (26 do sexo masculino e 17 do sexo feminino), com idades entre 4 e 83 anos, (média de 8 anos). A avaliação perceptivo-auditiva da nasalidade da fala foi feita por 6 fonoaudiólogos (3 com experiência em fissura e 3 sem experiência), os quais analisaram gravações das amostras de fala utilizando uma escala analógica visual (VAS-EAV) para indicar o grau de hipernasalidade, isto é, para cada amostra apresentada os fonoaudiólogos indicaram seus julgamentos num traçado de $100 \mathrm{~mm}$ onde uma extremidade foi 
identificada como normal e a outra como extremamente desviada. As amostras de fala utilizadas tanto para a análise perceptivo-auditiva quanto para a nasometria foram coletadas simultaneamente durante a produção de um texto envolvendo a distribuição normal dos fonemas (texto normal) e de outro texto livre de consoantes nasais (texto oral). Os autores reportaram para o texto normal a média de escore de nasalância de $51 \%$ e para o texto oral a média de $40 \%$. Os autores não reportaram os achados da escala VAS-EAV para a avaliação da nasalidade de fala, apenas indicaram o valor de concordância inter-julgadores $(r=0,49)$. Segundos os autores os achados deste estudo revelaram que a correlação entre o valor médio de nasalância e o julgamento perceptivo da hipernasalidade (na escala VAS-EAV) variou entre o mínimo de 0,31 e o máximo de 0,56 (média $=0,43$ para o texto normal e um mínimo de 0,36 e o máximo de 0,60 (média $=0,54$ ) para o texto oral. Os autores também reportaram uma média de correlação para os 3 julgadores com experiência de 0,42 e para os 3 julgadores sem experiência de 0,43 . Os autores concluíram que a correlação entre nasalância e avaliação perceptivo-auditiva da hipernasalidade neste estudo foi baixa, sugerindo que os valores de nasalância devem ser interpretados cautelosamente e que a nasometria não deve ser usada como um substituto para avaliação perceptiva.

LEWIS et al. (2003) avaliaram a relação entre nasalância e nasalidade controlando a experiência clínica dos julgadores. Participaram do julgamento perceptivo-auditivo 12 adultos representando 4 níveis de experiência clínica quanto à avaliação perceptivo-auditiva da fala de indivíduos com fissura palatina. Três julgadores eram professoras sem treino acadêmico e 
sem experiência; 3 eram estudantes de um curso de fonoaudiologia com treinamento acadêmico-clínico, mas sem experiência profissional; 3 eram cirurgiões craniofaciais com muita experiência em ouvir a fala de indivíduos com fissura, mas sem nenhum treino específico quanto à avaliação perceptivoauditiva; 3 eram fonoaudiólogos com muito treino e experiência. Amostras de fala foram coletadas simultaneamente para a nasometria e para a análise perceptivo-auditiva durante a produção de uma única frase contendo somente fonemas orais. Vinte indivíduos com idades variando entre 4 e 18 anos com nasalidade variando entre normal e severamente hipernasal participaram das gravações, sendo que 17 apresentavam disfunção velofaríngea e 3 ressonância de fala normal. A avaliação perceptivo-auditiva foi realizada por meio de uma escala de 5 pontos (variando de $1=$ normal a $5=$ hipernasalidade severa). A concordância inter-julgadores variou entre 0,52 e 0,76 para os julgamentos perceptivo-auditivos da nasalidade. Tanto a média quanto a mediana dos achados perceptivo-auditivos foram apresentadas para os 4 grupos: para os fonoaudiólogos foi encontrada média de 2,5 e mediana de 2; para os cirurgiões, média de 2,6 e mediana de 3; para os estudantes, média de 2,7 e mediana de 3; para as professoras, média de 2,8 e mediana de 3. Diferença estatisticamente significante somente foi obtida entre os fonoaudiólogos e os professores. Os resultados revelaram também que a correlação entre nasalidade e nasalância variou entre 0,29 e 0,57, correlação esta considerada de baixa para moderada pelos autores. Os autores concluíram que a concordância para os achados perceptivo-auditivos é maior entre os julgadores mais experientes com a fala de indivíduos com fissura (fonoaudiólogos e cirurgiões) do que entre os julgadores sem experiência 
(estudantes e professores), sendo que os julgadores sem experiência tendem a julgar a fala como mais nasalisada do que os julgadores com experiência.

HIRSCHBERG et al. (2006) estudaram a correlação entre nasalidade e nasalância em amostras de fala de 30 crianças húngaras, com idades variando entre 5 e 7 anos, sendo que todas apresentavam problemas fonoaudiológicos os quais não foram especificados pelos autores. Para a análise da correlação tanto os valores de nasalância quanto os de nasalidade foram obtidos durante a produção de uma frase contendo apenas fonemas orais (frase oral) e uma frase (contendo fonemas orais e nasais (mista). A avaliação perceptivo-auditiva da nasalidade foi realizada por 36 julgadores usando uma escala de 3 pontos, na qual 3 indicava hipernasalidade severa, 2 hipernasalidade moderada e 1 hipernasalidade leve. Todos os julgadores eram falantes nativos do idioma húngaro sendo 12 fonoaudiólogos, 12 estudantes de fonoaudiologia e 12 pessoas leigas. Para a nasalância foram encontrados o valor médio de $11 \%$ para a sentença oral e de $31,7 \%$ para a sentença mista. Os autores não descreveram os achados perceptivo-auditivos e apenas indicaram ter encontrado uma correlação significante entre nasalância e nasalidade. Concluíram que os achados nasométricos podem complementar tanto o diagnóstico quanto a terapia fonoaudiológica, pediátrica e otorrinolaringológica. 


\section{Tabela 1 - Estudos que investigaram relação entre nasalância e julgamentos perceptivo-auditivos da nasalidade}

\begin{tabular}{|c|c|c|c|c|c|}
\hline & Amostra & $\begin{array}{l}\text { Perceptivo - } \\
\text { Auditivo } \\
\end{array}$ & Eficácia & $\begin{array}{l}\text { Julgamento } \\
\text { Perceptivo } \\
\end{array}$ & Correlação \\
\hline $\begin{array}{l}\text { Dalston e } \\
\text { Seaver } \\
(1992)\end{array}$ & $\begin{array}{l}\text { texto oral e } \\
\text { misto } \\
\text { sentenças } \\
\text { nasais }\end{array}$ & $\begin{array}{l}\text { escala de } 6 \\
\text { pontos }\end{array}$ & & & $\begin{array}{l}\text { ALTA: Significante: nasalância } X \text { sentenças } \\
\text { nasais } X \text { medidas da área nasal; nasalância X } \\
\text { hiponasalidade nasalância } X \text { texto oral } X \text { área } \\
\text { velofaríngea, nasalância } X \text { hipernasalidade. Não } \\
\text { significante: nasalância } X \text { texto oral/nasal } X \text { área } \\
\text { velofaríngea, nem entre área nasalX hiper e } \\
\text { hiponasalidade }\end{array}$ \\
\hline $\begin{array}{l}\text { Dalston } \\
\text { (1993) }\end{array}$ & $\begin{array}{l}\text { "Zôo Passage" } \\
\text { "El bosque" }\end{array}$ & $\begin{array}{l}\text { escala de } 6 \\
\text { pontos }\end{array}$ & $\begin{array}{l}\text { sensibilidade }=87 \% \\
\text { especificidade }=86 \%\end{array}$ & & ALTA: 0,78 \\
\hline Dutka (1996) & $\begin{array}{l}\text { Palavra } \\
\text { "bebê"e frase } \\
\text { "O bebê } \\
\text { babou" }\end{array}$ & 10 juízes & $\begin{array}{l}\text { sensibilidade }=100 \% \\
\text { (todos os grupos) } \\
\text { especificidade }=40 \% \text {, } \\
29 \% \text { (A) } 50 \% \text { e } 42 \% \text { (B) } \\
\text { e } 50 \% \text { e } 60 \% \text { (C) }\end{array}$ & & $\begin{array}{l}\text { ALTA e MODERADA: } \\
0,73 \text { e } 0,61 \text { grupo A } \\
0,80 \text { e } 0,73 \text { grupo B } \\
0,81 \text { e } 0,88 \text { grupo } C\end{array}$ \\
\hline $\begin{array}{l}\text { Waterson } \\
\text { (1998) }\end{array}$ & $\begin{array}{l}9 \text { sentenças } \\
\text { (baixa } \\
\text { pressão) Texto } \\
\text { (alta pressão) }\end{array}$ & $\begin{array}{l}7 \text { juízes } \\
\text { experientes } \\
\text { escala de } 7 \\
\text { pontos }\end{array}$ & $\begin{array}{l}\text { valor de corte de } 26 \% \\
\text { sensibilidade }=84 \% \\
\text { especificidade }=88 \%\end{array}$ & & ALTA: 0,77 (baixa pressão) 0,78 (alta pressão) \\
\hline $\begin{array}{l}\text { Hirschberg et } \\
\text { al. (2006) }\end{array}$ & $\begin{array}{l}1 \text { frase oral } 1 \\
\text { frase mista }\end{array}$ & $\begin{array}{l}36 \text { juízes escala } \\
\text { de } 3 \text { pontos }\end{array}$ & & & ALTA: 0,90 \\
\hline $\begin{array}{l}\text { Waterson } \\
\text { (1996) }\end{array}$ & $\begin{array}{l}\text { "Zôo Passage" } \\
\text { "Turtle" } \\
\text { "Mouse" }\end{array}$ & $\begin{array}{l}8 \text { juízes /escala } \\
\text { de } 5 \text { pontos }\end{array}$ & $\begin{array}{l}\text { Valor de corte } 22 \% 2,25 \\
\text { para hipernasalidade } \\
\text { Sensibilidade "Zôo" = } \\
72 \% \text { "Turtle" = } 83 \%\end{array}$ & & $\begin{array}{l}\text { MODERADA: "Zôo" }(0,70) \text { "turtle" }(0,51) \text { BAIXA } \\
\text { "Mouse" }(0,32)\end{array}$ \\
\hline $\begin{array}{l}\text { Keuning et al. } \\
(2002)\end{array}$ & $\begin{array}{l}\text { texto normal } \\
\text { texto oral }\end{array}$ & $\begin{array}{l}6 \text { juízes/ Escala } \\
\text { VAS }\end{array}$ & & $\begin{array}{l}\text { Concordância } \\
\text { inter-juízes } \\
(0,49)\end{array}$ & $\begin{array}{l}\text { MODERADA: } \text { média }=0,57 \text { texto normal e média } \\
=0,54 \text { texto oral }\end{array}$ \\
\hline $\begin{array}{l}\text { Lewis et al. } \\
\text { (2003) }\end{array}$ & & $\begin{array}{l}12 \text { juizes com } 4 \\
\text { níveis de } \\
\text { experiência } \\
\text { clínica/ escala de } \\
5 \text { pontos }\end{array}$ & & $\begin{array}{l}\text { concordância } \\
\text { inter-juízes (mín } \\
\text { de } 0,52 \text { e máx } \\
\text { de } 0,76 \text { ) }\end{array}$ & MODERADA: correlação variou entre 0,29 e 0,57 \\
\hline
\end{tabular}

\begin{tabular}{|c|c|c|c|c|c|}
\hline $\begin{array}{l}\text { Nelis et al. } \\
\text { (1992) }\end{array}$ & $\begin{array}{l}4 \text { sentenças } \\
\text { orais } 3 \\
\text { sentenças } \\
\text { mistas }\end{array}$ & $\begin{array}{l}10 \text { juízes } 2 \\
\text { escalas de } 6 \\
\text { pontos }(1 \mathrm{p} / \\
\text { hipernasalida-de }) \\
(1 \mathrm{p} / \\
\text { hiponasalidade })\end{array}$ & & & $\begin{array}{l}\text { BAIXA: Significante: nasalância } \times \text { hiponasalidade } \\
\text { ( } 3 \text { sentenças mistas }-0,65 ;-0,54 ;-0,62) \\
\text { nasalância e hipernasalidade ( } 4 \text { sentenças orais e } \\
3 \text { mistas Não significante) }\end{array}$ \\
\hline $\begin{array}{l}\text { Hardin et al. } \\
\text { (1992) }\end{array}$ & $\begin{array}{l}\text { sentenças } \\
\text { nasais/ "Zôo } \\
\text { Passage" }\end{array}$ & $\begin{array}{l}3 \text { juízes escala de } \\
7 \text { pontos } \\
\text { compararam os } \\
\text { valores de corte } \\
\text { de } 32 \%, 26 \% \text { e } \\
50 \%\end{array}$ & $\begin{array}{l}\text { escore } 32 \%=60 \% \\
\text { escore } 26 \%=87 \%\end{array}$ & $\begin{array}{l}\text { escore } 32 \%= \\
97 \% \\
\text { escore } 26 \%= \\
93 \%\end{array}$ & CORRELAÇÃO NÃO ESTUDADA \\
\hline $\begin{array}{l}\text { Waterson } \\
\text { (1999) }\end{array}$ & $\begin{array}{l}\text { palavras e } \\
\text { frases } 2,6, \\
17 \text { sílabas e } 1 \\
\text { texto }\end{array}$ & & & & $\begin{array}{lr}\text { CORRELAÇÃO ENTRE OS TEXTOS } & =0,95 \\
\text { entre texto e frases com } 17 \text { sílabas } & 0,93 \\
\text { entre texto e as frases com } 6 \text { sílabas } & 0,85 \\
\text { entre texto e palavra de } 2 \text { sílabas } & \end{array}$ \\
\hline $\begin{array}{l}\text { Dalston et al. } \\
\text { (1991) }\end{array}$ & texto oral & $\begin{array}{l}1 \text { juiz escala de } 6 \\
\text { pontos }\end{array}$ & $\begin{array}{l}\text { Valor de corte }=32 \% \\
\text { sensibilidade }=89 \% \\
\text { especificidade }=95 \%\end{array}$ & & CORRELAÇÃO NÃO ESTUDADA \\
\hline
\end{tabular}



4 MATERIAIS E MÉTODOS 



\section{MATERIAIS E MÉTODOS}

Este estudo propôs estabelecer a correlação entre medidas de nasalância e julgamento perceptivo-auditivo da nasalidade em uma amostra de fala do Português Brasileiro. Para tal propôs-se uma análise de amostras de fala pré-existentes, constituindo, portanto, um estudo retrospectivo.

\subsection{Participantes}

Para a seleção das amostras de fala de interesse para este estudo, inicialmente foi realizada uma investigação no banco de dados de pacientes do convênio entre o Hospital de Reabilitação de Anomalias Craniofaciais da Universidade de São Paulo (HRAC-USP) e o Centro Craniofacial da Universidade da Flórida (UFCFC), que apresentassem as seguintes características:

- $\quad$ Idades entre 4 e 9 anos;

- $\quad$ Fissura unilateral de lábio e palato, operada do palato entre 12 e 18 meses de idade; pelas técnicas cirúrgicas de Von Langenbeck ou Furlow;

- $\quad$ Hipernasalidade de fala;

- $\quad$ Ausência de síndromes associadas à fissura, ou quaisquer condições clínicas que colocassem em risco o desenvolvimento da fala como deficiência auditiva, ou deficiência mental, por exemplo; 
- Ausência de fístula de palato e de histórico de cirurgias secundárias para correção de insuficiência velofaríngea.

Que apresentaram os critérios de inclusão descritos acima nesta primeira pré-seleção foram 120 crianças. Como era necessário que estas crianças também já tivessem medidas de nasalância obtidas simultaneamente às gravações de áudio, assim como tivessem avaliação perceptivo-auditiva da nasalidade de fala realizada no mesmo dia da avaliação nasométrica, ao final encontramos 79 crianças que preenchiam mais esses critérios de inclusão. Portanto, estas 79 crianças é que efetivamente fizeram parte da amostra do presente estudo. Assim, todas apresentavam então, fissura unilateral de lábio e palato, tinham idades variando entre 4 e 9 anos (média= 6,5 $\pm 2,9$ anos), eram operadas do palato entre 12 e 18 meses de idade e apresentavam avaliação perceptivo-auditiva da nasalidade, avaliação nasométrica e gravação de áudio. Embora as crianças tenham sido submetidas a uma avaliação fonoarticulatória completa, foi coletado de seus prontuários apenas o resultado da avaliação perceptivo-auditiva quanto à presença de hipernasalidade bem como a classificação de seus níveis como: leve, moderada ou severa, obtidos por meio de conversa espontânea com 0 avaliador. Um total de 79 crianças apresentaram as condições aqui descritas. 


\subsection{Estímulo de Fala}

As 79 avaliações nasométricas realizadas simultaneamente às gravações de áudio, previamente armazenadas no banco de dados do Laboratório de Fonética Experimental (LAFE) do HRAC/USP, foram o objeto de estudo deste trabalho. Das gravações de áudio pré-existentes no banco de dados selecionamos para este estudo as palavras: "papai" e "bebê", e as frases "Papai pediu pipoca" e o "O bebê babou".

\subsection{Procedimentos para Gravação das Amostras de Fala}

As palavras e frases descritas acima foram repetidas 2 vezes cada uma após o avaliador e gravadas em áudio simultaneamente à realização da nasometria. As emissões foram captadas por meio de um microfone de cabeça, condensado/unidirecional, modelo AKG C420, posicionado à aproximadamente $5 \mathrm{~cm}$ da comissura labial, e gravadas diretamente no computador Intel Pentium

4 (256MB RAM), equipado com placa de som modelo Creative Audigy II, utilizando-se o programa Sony Sound Forge, versão 7.0 (2003), com taxa de amostragem de $44100 \mathrm{~Hz}$, em monocanal, 16 Bits, gravadas em arquivos com extensão tipo wav. Todas as gravações foram realizadas em ambiente silencioso e acusticamente tratado. 


\subsection{Julgamento Perceptivo-Auditivo das Amostras de Fala}

Apesar de já existir no prontuário uma avaliação perceptivo-auditiva indicando que todas as 79 crianças apresentavam hipernasalidade em grau leve, moderado ou severo, as amostras deste estudo gravadas simultaneamente à nasometria foram novamente julgadas por três fonoaudiólogas experientes no diagnóstico e tratamento das alterações de fala decorrentes de fissura palatina, que a partir de agora denominaremos de julgadoras. Como os valores de nasalância foram obtidos durante a produção de um estímulo de fala de curta extensão (duas palavras e duas frases curtas) e os julgamentos perceptivo-auditivos do prontuário foram obtidos durante conversa espontânea, optou-se por classificar a nasalidade das mesmas amostras analisadas durante a nasometria.

Portanto para o julgamento perceptivo-auditivo as 79 gravações de áudio das duas palavras e duas das frases foram editadas pela autora utilizando-se o programa Sony Sound Forge 7.0 (2003). Cada emissão foi apresentada três vezes consecutivas mantendo-se um intervalo de 20 segundos entre as emissões. As gravações foram ordenadas de forma aleatória em um CD, constituindo de 316 amostras. Para análise da confiabilidade intra-julgadoras $35 \%$ desta amostra foi duplicada de forma aleatória e inserida no CD de forma também aleatória. O material apresentado para as três julgadoras, portanto, foi constituído de um total de 428 amostras de fala (79 gravações $X 2$ palavras e 2 frases $=316+112$ repetições $=428)$. 
As três julgadoras ouviram as gravações utilizando o programa Windows Media Player (Microsoft Windows) e fones de ouvido modelo Sennheiser HD 202. As mesmas foram orientadas a classificar a ressonância de fala, mais especificamente a nasalidade, e a identificar presença ou ausência de quaisquer outras alterações de fala que pudessem interferir com o valor de nasalância ou com a classificação da nasalidade. Cada emissão foi classificada individualmente por meio de numa escala de 4 pontos, na qual 1 indicou nasalidade normal, 2 indicou hipernasalidade leve, 3 hipernasalidade moderada e 4 hipernasalidade severa. Ainda nesta classificação cada julgadora tinha a opção de assinalar "não sei". A opção "não sei" foi incluída de forma a não tendenciar os julgamentos permitindo que a julgadora indicasse que mesmo após ouvir uma amostra várias vezes ainda assim não conseguiu julgar a nasalidade da mesma. Vale ressaltar que esta última opção não foi incluída para o cálculo da média do julgamento perceptivo-auditivo da nasalidade.

Os julgamentos foram feitos individualmente em ambiente silencioso, durante o tempo em que as julgadoras considerassem necessário para chegarem a uma conclusão quanto aos aspectos a serem julgados. Durante os julgamentos foram permitidos todos os ajustes no volume de áudio e na repetição da apresentação das amostras que as julgadoras considerassem necessários para que o julgamento fosse o mais preciso possível. A ordem de apresentação foi a mesma para todas as julgadoras. Apesar da possibilidade das mesmas apresentar algum tipo de contato anterior com as crianças do presente estudo (por se tratarem de fonoaudiólogas do HRAC), nenhuma delas 
tinha conhecimento a respeito do presente estudo. A autora deste estudo não participou como julgadora.

Os coeficientes de concordância intra-julgadores e inter-julgadores foram calculados. Concordância intra-julgador ou variabilidade intraobservador, segundo JEKEL et al. (2005), é a medida da consistência ou da inconsistência entre avaliações repetidas feitas por um mesmo avaliador, enquanto concordância inter-julgador ou variabilidade inter-observador é a medida da concordância/discordância entre diferentes avaliadores. Neste estudo a interpretação dos coeficientes de concordância Kappa FLEISS (1973) foi realizada segundo a proposta de LANDIS E KOCH (1977), da seguinte forma:

- < que 0,00 não indica concordância

- de 0,00 a 0,20 indica concordância pequena

- de 0,21 a 0,40 indica concordância regular

- de 0,41 a 0,60 indica concordância moderada

- de 0,61 a 0,80 indica concordância substancial

- de 0,81 a 1,00 indica concordância perfeita (ou quase perfeita)

\subsubsection{Concordância Intra-julgadoras}

Conforme descrito anteriormente, $35 \%$ das amostras de fala foram repetidas e distribuídas aleatoriamente no $C D$ apresentado às três julgadoras para análise perceptivo-auditiva das amostras. Para obtenção da concordância intra-julgadoras obteve-se o coeficiente de concordância Kappa para as 
amostras que foram analisadas duas vezes pela mesma julgadora, e cada uma das 3 foi comparada com ela mesma.

O resultado da análise da concordância intra-julgadoras está descrito na Tabela 2. Ao considerarmos todas as julgadoras e todos os estímulos observamos uma concordância intra-julgadoras de 76\% para as 112 (35\%) amostras duplicadas no CD apresentado para julgamento perceptivoauditivo. Para a julgadora 1 verificamos que a concordância dela com ela mesma variou de $69 \%$ a $76 \%$ (média $=74 \%$ ), sendo menor para a palavra "bebê" e maior para a palavra "papai". Para a julgadora 2 verificamos que a concordância dela com ela mesma variou de $71 \%$ a $79 \%$ (média $=74 \%$ ), sendo menor para as duas palavras e maior para a frase "Papai pediu pipoca". Para a julgadora 3 verificamos que a concordância dela com ela mesma variou de $79 \%$ a $86 \%$, (média $=81 \%$ ), sendo menor para as duas palavras e maior para as duas frases.

Tabela 2 - Valores expressos em porcentagem quanto à concordância intrajulgadoras de acordo com o julgamento perceptivo-auditvo

\begin{tabular}{lcccc}
\hline \multicolumn{1}{c}{ Concordância } & \multicolumn{3}{c}{ Inter Julgadoras } \\
Amostra & $\# \mathbf{1}$ & $\# \mathbf{2}$ & $\# \mathbf{3}$ & Média \\
\hline Papai & $76 \%$ & $71 \%$ & $79 \%$ & $75 \%$ \\
Bebê & $69 \%$ & $71 \%$ & $79 \%$ & $73 \%$ \\
Papai pediu pipoca & $75 \%$ & $79 \%$ & $82 \%$ & $79 \%$ \\
O bebê babou & $75 \%$ & $75 \%$ & $86 \%$ & $79 \%$ \\
\hline Todos estímulos & $74 \%$ & $74 \%$ & $81 \%$ & $76 \%$ \\
\hline
\end{tabular}


Ao observarmos as quatro diferentes amostras de fala, verificamos que a concordância intra-julgadoras foi melhor para a frase "O bebê babou" (86\%), seguida da frase "Papai pediu pipoca" (82\%), tendo sido um pouco menor para as palavras "papai" e "bebê" (79\%). Com exceção da julgadora 1, para a palavra "bebê", a concordância intra-julgadoras neste estudo esteve sempre acima de $70 \%$, um valor indicado como aceitável na literatura. A julgadora 3 apresentou melhor concordância do que as outras.

Usando-se a interpretação dos coeficientes Kappa sugerida por Landis e Koch (1977) verificamos que a concordância intra-julgadoras neste estudo variou de moderada a substancial. Isto é, a concordância entre as três julgadoras foi menor do que a concordância de cada julgadora com ela mesma.

\subsubsection{Concordância Inter-julgadoras}

Para obtenção da concordância inter-julgadoras obtivemos o coeficiente de concordância Kappa pareando-se os achados de uma julgadora com cada uma das outras duas o que resultou em 3 pares (1 e 2; 1 e $3 ; 2$ e 3 ). Os resultados, apresentados na Tabela 3, demonstram que a concordância para a palavra "papai" entre as julgadoras 1 e 2 foi de $74 \%$, entre as julgadoras 1 e 3 foi de $69 \%$ e entre as julgadoras 2 e 3 foi de $69 \%$. Para a palavra "bebê, a concordância de $70 \%$ foi obtida entre as julgadoras 1 e 2; $60 \%$ entre as julgadoras 1 e 3 e 66\% entre as 2 e 3 . Para a frase "Papai pediu pipoca", a concordância foi de $63 \%$ entre as julgadoras 1 e 2; $57 \%$ entre 1 e 3 e $67 \%$ 
entre as 2 e 3. Para a frase "O bebê babou", a concordância foi de $63 \%$ entre as julgadoras 1 e 2, $57 \%$ entre as 1 e 3 e $62 \%$ entre as 2 e 3 .

Tabela 3 - Valores expressos em porcentagem quanto à concordância interjulgadoras de acordo com o julgamento perceptivo-auditvo

\begin{tabular}{lccc}
\hline $\begin{array}{l}\text { Amostras } \\
\text { de fala }\end{array}$ & \multicolumn{2}{c}{ Concordância inter julgadoras } \\
& $\mathbf{1 \times 2}$ & $\mathbf{1 \times 3}$ & $\mathbf{2 \times 3}$ \\
\hline Papai & $74 \%$ & $69 \%$ & $69 \%$ \\
Bebê & $70 \%$ & $60 \%$ & $66 \%$ \\
Papai pediu pipoca & $63 \%$ & $57 \%$ & $67 \%$ \\
O bebê babou & $63 \%$ & $57 \%$ & $62 \%$ \\
\hline
\end{tabular}

Usando-se a interpretação dos coeficientes Kappa sugerida por Landis e Koch (1977) verificamos que a concordância inter-julgadoras, neste estudo, variou de substancial a quase perfeita. Isto é, a concordância entre as três julgadoras foi menor do que a concordância de cada julgadora com ela mesma.

Os achados perceptivos para cada um dos estímulos usados neste estudo são apresentados conforme a concordância inter-julgadoras.

Para a palavra "papai", $45(57 \%)$ do total das amostras foram julgadas pelas 3 julgadoras com total concordância, sendo que 38 (48\%) foram 
julgadas como nasalidade normal, 5 (6\%) como hipernasal leve e 2 (3\%) como hipernasal moderada. Duas das três julgadoras (2 de 3), julgaram 12 (15\%) das amostras como nasalidade normal, 13 (16\%) como hipernasal leve e $3(4 \%)$ como hipernasal moderada. Houve total discordância quanto ao julgamento de $6(8 \%)$ amostras de fala.

Para a palavra "bebê", $39(49 \%)$ do total da amostra foram julgadas pelas três julgadoras com total concordância, sendo que 33 (41\%) foram julgadas como nasalidade de fala normal, 4 (5\%) como hipernasal leve e 2 (3\%) como hipernasal moderada. Duas das três julgadoras concordaram no julgamento de 34 (43\%) amostras, sendo que 13 (16\%) dessas foram julgadas como nasalidade normal, 19 (24\%) como hipernasal leve e 2 (3\%) com hipernasal moderada. Houve total discordância quanto ao julgamento de 6 (8\%) amostras de fala.

Para a frase "Papai pediu pipoca", 37 (47\%) das amostras foram julgadas pelas três julgadoras com total concordância, sendo que 29 (37\%) foram julgadas como nasalidade de fala normal, 6 (7\%) como hipernasal leve e 2 (3\%) como hipernasal moderada. Duas das três julgadoras concordaram no julgamento de 35 (44\%) amostras, sendo que 13 (16\%) dessas amostras foram julgadas como nasalidade normal, 20 (25\%) como hipernasal leve e 2 (3\%) como hipernasal moderada. Houve total discordância quanto ao julgamento de $7(9 \%)$ amostras de fala. 
Para a frase "O bebê babou", 34 (43\%) amostras foram julgadas pelas três julgadoras com total concordância, sendo que 26 (33\%) foram julgadas como nasalidade de fala normal, $6(7 \%)$ como hipernasal leve e 2 (3\%) como hipernasal moderada. Duas das três julgadoras concordaram em relação ao julgamento de $40(51 \%)$, sendo $17(21 \%)$ das amostras como nasalidade normal, $21(27 \%)$ como hipernasal leve e $2(3 \%)$ com hipernasal moderada. Houve total discordância quanto ao julgamento de 5 (6\%) amostras de fala.

\subsubsection{Interpretação dos Julgamentos Perceptivo-Auditivos}

Para interpretar os resultados perceptivos calculamos a média aritmética dos três julgamentos de nasalidade para as duas palavras e duas frases independentemente do grau de hipernasalidade. Para interpretar as médias dos julgamentos perceptivo-auditivos e para calcular a eficácia do nasômetro em confirmar estes achados, consideramos a média de 1,5 como valor de corte, isto é, valores abaixo de 1,5 (na escala de 4 pontos) foram interpretados como indicativos de nasalidade normal e valores de 1,5 ou mais foram interpretados como indicativos de hipernasalidade. Tal decisão, apesar de arbitrária, levou em consideração o fato de relatos clínicos indicarem que certo grau de hipernasalidade leve é comumente encontrado em alguns falantes normais. A partir do cálculo das médias dos julgamentos perceptivos, portanto, as amostras passaram a ser interpretadas somente como normais ou hipernasais. 
Após calculada a média dos julgamentos das três julgadoras, as amostras foram subdivididas em três grupos (A, B, e C):

- no Grupo $\boldsymbol{A}$ foram incluídas apenas as amostras julgadas com 100\% de concordância entre as julgadoras,

- no Grupo B foram incluídas apenas as amostras as quais houve concordância entre duas das três julgadoras,

- no Grupo $\boldsymbol{C}$ foram incluídas apenas as amostras as quais houve total discordância entre as três julgadoras.

Também fizemos a comparação entre a média obtida no julgamento perceptivo-auditivo entre as três julgadoras para cada amostra de fala com o valor do julgamento perceptivo-auditivo que constava no prontuário de cada paciente.

\subsection{Procedimentos para Captação, Armazenamento e Cálculo dos Dados da Nasometria}

A avaliação nasométrica foi realizada por várias fonoaudiólogas experientes na realização de nasometria, utilizando o nasômetro, Modelo 62002, Pentium Byte On fabricado pela Kay Elemetrics (1992). O equipamento consiste num sistema operado por microcomputador, no qual as energias acústicas, oral e nasal, da fala são captadas por dois microfones direcionados à boca e ao nariz do indivíduo, separados por uma placa horizontal de metal posicionada acima do lábio superior (como se fosse um bigode) durante a 
gravação da amostra de fala. No LAFE-HRAC-USP a placa com os microfones é mantida por uma haste de metal, numa adaptação feita por Dutka (1992). Esta adaptação é utilizada no LAFE com o objetivo de obter-se maior aceitação e colaboração na avaliação nasométrica principalmente por parte das crianças. $\mathrm{Na}$ configuração original, a placa com os microfones do nasômetro fica acoplada a um capacete a ser colocado na cabeça, o que pode provocar resistência por parte de crianças pequenas.

$\mathrm{Na}$ adaptação a placa com os microfones encontra-se acoplada a uma haste de metal que permite que a criança não de sinta presa à placa, podendo movimentar-se a repetição de cada estímulo. Cuidados foram tomados para que as crianças não se afastassem da placa durante a gravação nasométrica, conforme sugerido por DUTKA (Figura 1).

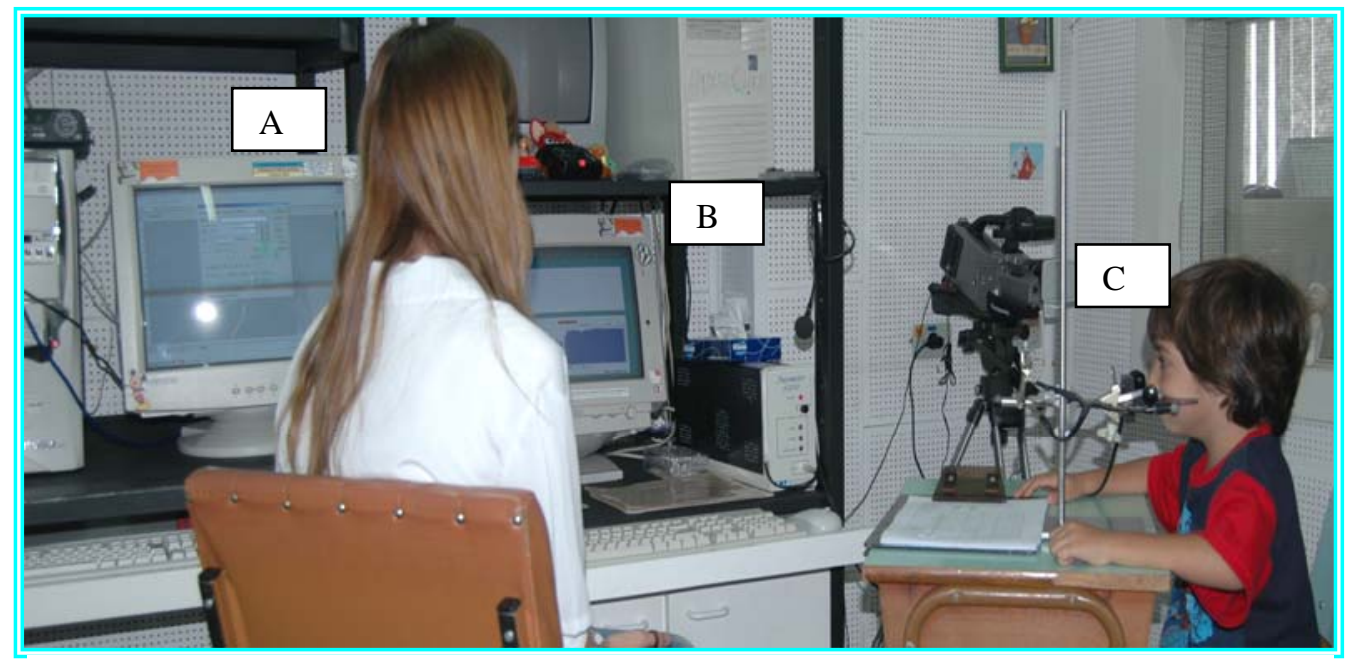

Fonte: Dutka (1992)

Figura 1 - Computador para as gravações e análise das amostras de audio das emissões (a), computador para as gravações e análise das nasometrias (b), e placa separadora de som com os microfones 
Durante a captação o sinal de cada um dos microfones é filtrado e digitalizado por módulos eletrônicos e processados por um software específico para nasometria, o qual calcula a nasalância que corresponde a uma razão numérica entre o nível de pressão sonora (NPS) nasal dividido pela soma do NPS nasal e oral, multiplicada por 100, de forma a expressar um valor que corresponde a uma porcentagem da energia nasal em relação a energia total.

(NPS nasal / NPS nasal + NPS oral) x 100 = nasalância \%

A calibração do nasômetro, os procedimentos de gravação e os cálculos das medidas de nasalância para cada criança, foram realizados de acordo com os procedimentos descritos no Manual de Instrução do Nasômetro (Kay Elemetrics, 1992). A assepsia da base de metal foi realizada com algodão embebido em álcool 70, antes de cada exame.

Durante a captação cada criança ficou sentada numa cadeira confortável, em uma sala isolada acusticamente no LAFE. A cada uma, foi solicitada a repetição das duas palavras e duas frases em voz habitual após modelo produzido pela avaliadora. Foram considerados para a análise, os valores da nasalância média da primeira emissão tecnicamente aceitável de cada palavra e frase, ou seja, produzida sem erros e dentro do limite de intensidade aceita do instrumento (Manual de Instruções Kay Elemetrics,1992). A calibração do nasômetro foi realizada diariamente, antes do início dos exames. Obtidas as amostras, as mesmas foram armazenadas em arquivos 
individuais no computador conectado ao nasômetro e os valores de nasalância, para cada amostra, foram calculados para cada criança.

\subsubsection{Escore de nasalância}

O escore de nasalância é calculado automaticamente usando-se o software do instrumento. Mais especificamente, após a energia acústica dos dois microfones ser transformada em um escore de nasalância a mesma é apresentada na tela do computador em forma de um gráfico onde, no eixo vertical está representado o grau de nasalância em porcentagem (de um mínimo de 0 ao máximo de $100 \%$ ) e no eixo horizontal está representada a duração da amostra analisada.

Na Figura 2 observa-se a representação gráfica obtida durante nasometria de uma amostra de fala, onde no trecho indicado pelo número "1" está representada uma amostra de fala contendo apenas fonemas orais /papapa/ e no trecho indicado pelo número "2" está representada uma amostra de fala contendo apenas fonemas nasais /mamama/. 


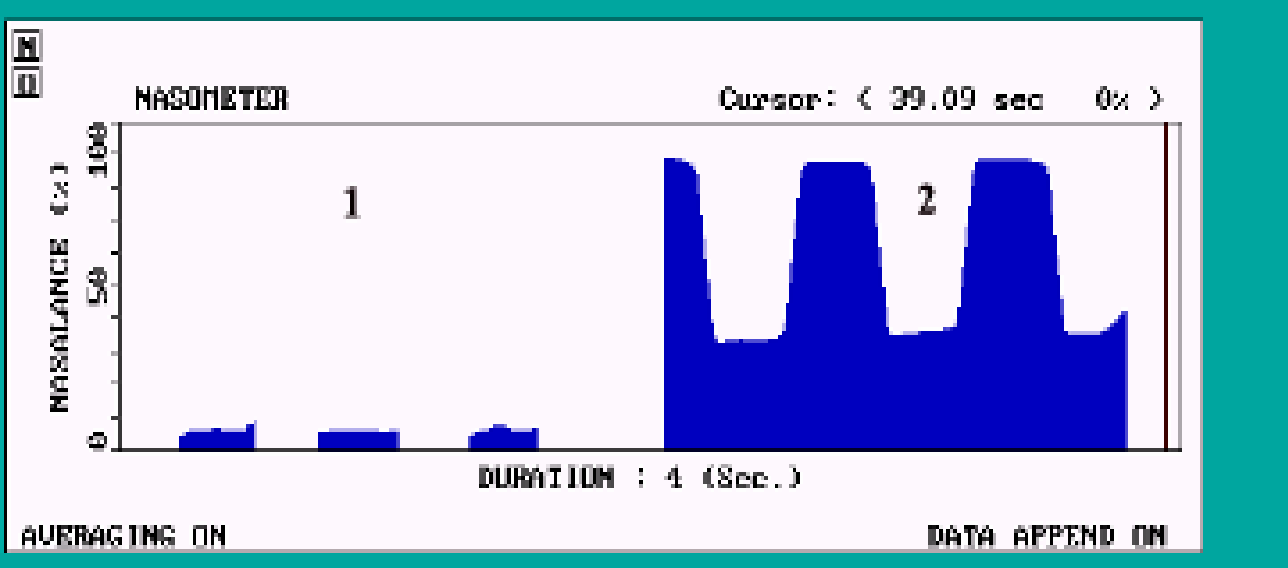

Fonte: Figura adaptada de Lima, 2006, com permissão

Figura 2 - Gráfico apresentado na tela do computador a partir do software de análise do nasômetro 6200-2 (Kay Elemetrics Corp.), onde "1" representa, a emissão de /pa pa pa/ e "2" representa a emissão de /ma ma ma/.

O cálculo da nasalância é feito automaticamente pelo software (comando "analysis") quando o estímulo de fala capitado é marcado pelos dois cursores. A Figura 3 ilustra a tela do nasômetro com a análise de uma amostra de fala contendo apenas fonemas orais, enquanto a Figura 4 ilustra uma amostra de fala contendo apenas fonemas nasais. 


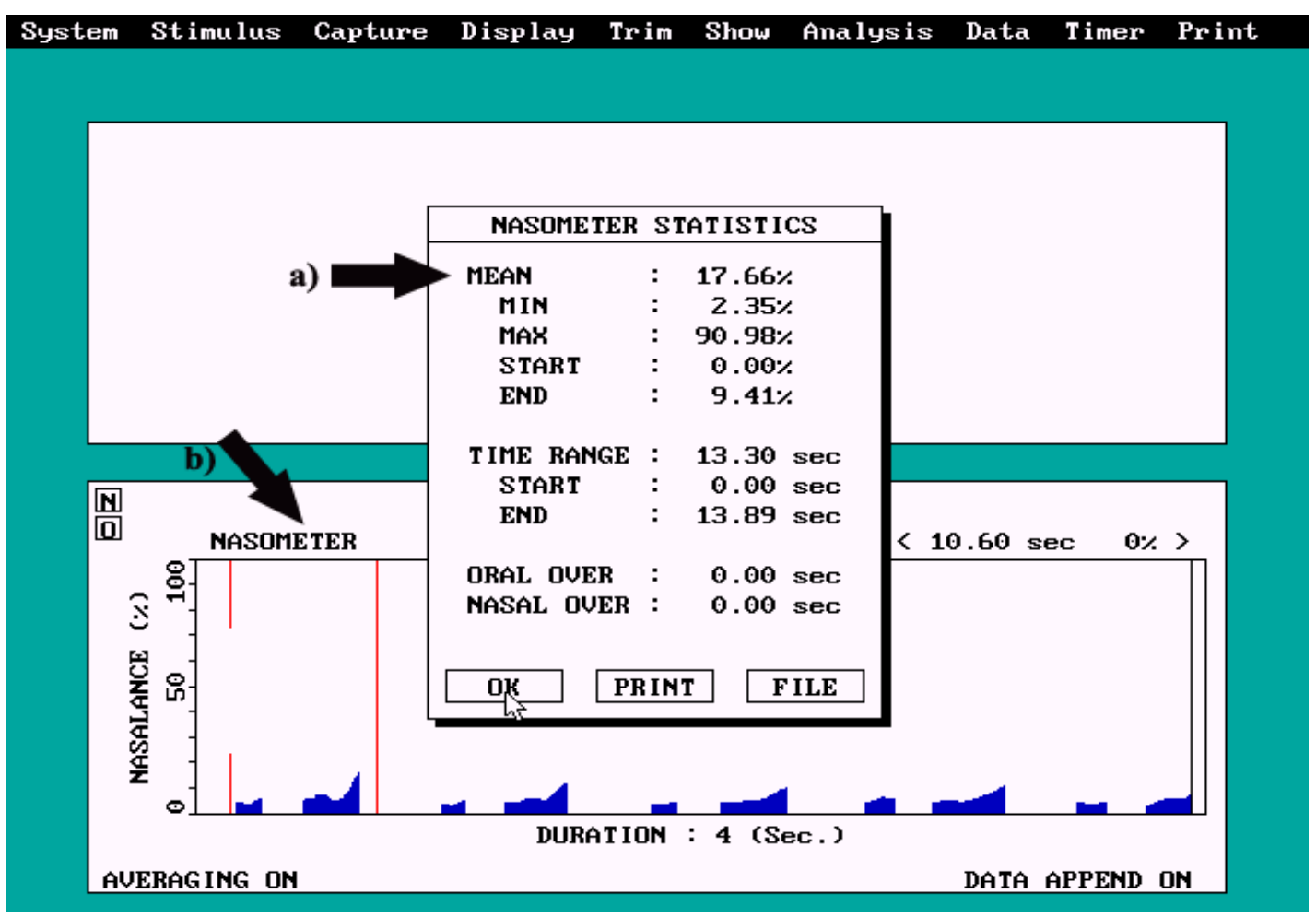

Fonte: Figura adaptada de Lima, 2006, com permissão

Figura 3 - Tela do computador gerada a partir do software de análise do nasômetro 6200-2 (Kay Elemetrics Corp.) ilustrando o valor médio de nasalância de 17,66\% identificado pela SETA "A", obtido para a amostra de fala composta apenas fonemas orais, selecionada pelos cursores identificados pela SETA "B"

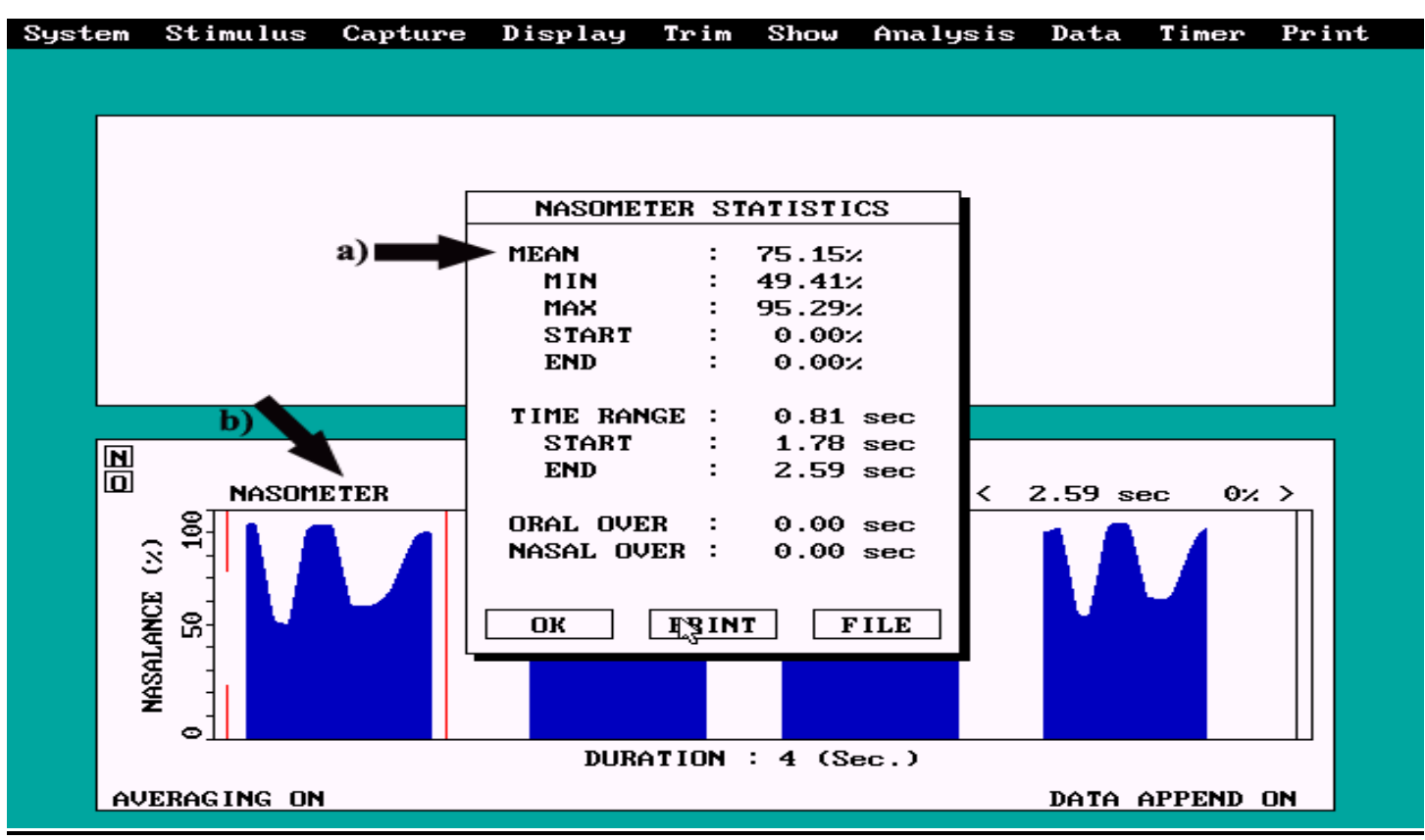

Fonte: Figura adaptada de Lima, 2006, com permissão

Figura 4 - Tela do computador gerada a partir do software de análise do Nasômetro 6200-3 (Kay Elemetrics Corp.), ilustrando o valor médio de nasalância de $75,15 \%$ identificado pela SETA "A", obtido para a amostra de fala contendo apenas fonemas nasais, selecionada pelos cursores identificados pela SETA " $B$ " 


\subsubsection{Eficácia do Nasômetro}

Numa situação ideal, segundo descreve PEGORARO-KROOK (2004), um teste quando eficiente deve ser capaz de distinguir, sem equívocos, entre a presença e a ausência da condição investigada. Esta habilidade, neste caso do nasômetro, de distinguir corretamente entre a presença ou a ausência da condição investigada, neste caso a nasalidade da fala, pode ser quantificada através da identificação dos índices de sensibilidade e de especificidade do instrumento fornecendo uma estimativa do valor da nasometria em corroborar os achados perceptivo-auditivos. Isto é, por meio da identificação destes índices, o examinador pode estabelecer o nível de eficiência do instrumento e, portanto, definir sua aplicabilidade clínica.

A sensibilidade do nasômetro (SN), mais especificamente, refere-se à freqüência com que o instrumento identificou a presença da hipernasalidade quando esta esteve realmente presente conforme o observado na avaliação perceptivo-auditiva da fala. A especificidade do nasômetro (EN) refere-se à freqüência que o instrumento identificou a ausência da hipernasalidade quando esta esteve realmente ausente, conforme indicado na avaliação perceptivoauditiva da fala.

A identificação destes índices (SN e EN) requer a seleção de um valor de corte de nasalância o qual permite separar os valores de nasalância indicativos da presença dos valores indicativos da ausência da condição em questão (hipernasalidade). Para obtenção dos índices de sensibilidade e de 
especificidade da nasometria no presente estudo optamos pelo uso do valor de corte de nasalância de 21\%, estabelecido por DUTKA, (1996).

Uma vez selecionado o valor de corte, foram determinados os índices de sensibilidade e de especificidade do nasômetro para as duas palavras e duas frases usadas como estímulo para coleta das amostras deste estudo. Assim, Sensibilidade neste estudo foi o produto da divisão entre o número de casos que tiveram presença de hipernasalidade (“a”) indicada pelo escore de nasalância igual ou acima de $21 \%$ e pelo julgamento perceptivoauditivo acima de 1,5 , dividido pela soma deste mesmo números de casos "a" mais o número de casos para os quais a avaliação perceptivo-auditiva indicou presença de hipernasalidade ("b"), porém os escores de nasalância foram menores de $21 \%$ indicando ausência de hipernasalidade. Especificidade foi calculada como sendo o produto da divisão entre o número de casos para os quais a avaliação perceptivo-auditiva e a nasalância indicaram ausência de hipernasalidade ("d") e a soma deste mesmo número mais o número de casos para os quais a avaliação perceptivo-auditiva indicou ausência de hipernasalidade, porém os escores de nasalância foram iguais ou acima de $21 \%$ (indicando presença de hipernasalidade). Os valores obtidos tanto para sensibilidade quanto para especificidade são multiplicados por 100 para serem expressos em porcentagem (\%). A Tabela 4 ilustra como foram calculados a sensibilidade e especificidade: 
Tabela 4 - Cálculo dos índices de sensibilidade e de especificidade do nasômetro na identificação da hipernasalidade

\begin{tabular}{c|ccc}
\hline \multicolumn{4}{c}{$\begin{array}{c}\text { Julgamento } \\
\text { Perceptivo-Auditivo }\end{array}$} \\
\hline $\begin{array}{c}\text { Perceptivo } \\
\text { Instrumento }\end{array}$ & $\begin{array}{c}\text { Hipernasalidade } \\
\text { Presente }\end{array}$ & $\begin{array}{c}\text { Hipernasalidade } \\
\text { Ausente }\end{array}$ & TOTAL \\
\hline $\begin{array}{c}\text { Neste Posalância } \geq 21 \% \\
\text { Teste Negativo } \\
\text { Nasalância }<21 \%\end{array}$ & $\mathrm{~A}$ & $\mathrm{~b}$ & $\mathrm{a}+\mathrm{b}$ \\
\hline TOTAL & $\mathrm{C}$ & $\mathrm{d}$ & $\mathrm{c}+\mathrm{d}$ \\
\hline
\end{tabular}

Sensibilidade $=a / a+c \times 100$

Especificidade $=\mathrm{d} / \mathrm{b}+\mathrm{d} \times 100$

\subsection{Análise Estatística dos Dados}

Após o julgamento perceptivo-auditivo, foi considerada a média das respostas dos três julgadoras. Valores médios acima de 1,5 foram interpretados como indicadores de hipernasalidade e valores de 1,5 ou menores foram interpretados como indicadores de nasalidade normal.

As médias dos julgamentos perceptivo-auditivos e os valores de nasalância foram organizados em forma de tabelas com medidas de posição e de variabilidade. Como medida de posição, foi utilizada a média e, de variabilidade, o desvio padrão (DP). Com o objetivo de estabelecer-se a relação entre os valores de nasalância e os julgamentos perceptivos, a média aritmética dos julgamentos perceptivos foi usada juntamente com a média de nasalância para o cálculo do Coeficiente de Correlação de Spearman. 
Inicialmente foi realizada a correlação entre as medidas de nasalância e a classificação da nasalidade previamente existente no prontuário. A seguir, foi realizada a correlação entre nasalância e nasalidade para as 79 crianças utilizando os julgamentos perceptivos obtidos pelas três julgadoras. Em seguida, o Coeficiente de Correlação de Spearman foi obtido para cada subgrupo: Grupo A, no qual houve concordância de 100\% entre as julgadoras, Grupo B no qual duas das três julgadoras concordaram e Grupo C, no qual houve total discordância entre as três julgadoras.

Para o cálculo da eficácia do nasômetro em confirmar os achados perceptivo-auditivos da nasalidade de fala a autora considerou a média aritmética de 1,5 como o valor de corte, isto é, valores abaixo de 1,5 (na escala de 4 pontos) foram interpretados como indicativos de nasalidade normal e valores de 1,5 ou mais foram interpretados como indicativos de hipernasalidade. Tal decisão, apesar de arbitrária, levou em consideração o fato de relatos clínicos indicarem que certo grau de hipernasalidade leve pode ser comumente encontrado em alguns falantes normais. 

5 RESULTADOS 



\section{Resultados}

O objetivo deste estudo foi o de estabelecer a correlação entre medidas de nasalância e julgamento perceptivo-auditivo da nasalidade em uma amostra de fala do Português Brasileiro. A medida da eficácia do nasômetro em corroborar os achados perceptivo-auditivos também foi obtida.

Primeiro serão apresentados os valores de nasalância e os resultados dos julgamentos perceptivo-auditivos. Em seguida, serão apresentados os resultados da análise da correlação entre nasalância e nasalidade e, finalmente, as medidas da eficácia do nasômetro.

\subsection{Julgamento Perceptivo-Auditivo}

Os valores atribuídos aos julgamentos perceptivo-auditivos contidos nos prontuários variaram de 2 a 4 , com média de 2,3 (DP = 0,50). Os valores atribuídos aos julgamentos obtidos pelas três julgadoras variaram de 1,0 a 3,3 tanto para as palavras como para as frases. Especificamente para a palavra "papai" a média foi de 1,43 (DP = 0,63), para "bebê"; a média foi de 1,48 (DP = 0,61) para a frase "Papai pediu pipoca" a média foi de $1,53(\mathrm{DP}=0,59)$ e para a frase "O bebê babou" a média foi de 1,52 (DP = 0,59) (vide Tabela 5). 
Tabela 5 - Médias dos julgamentos perceptivo-auditivos por julgadoras e média do julgamento perceptivo auditivo do prontuário

Perceptivo-Auditivo

\begin{tabular}{cccccc} 
& Papai & Bebê & $\begin{array}{c}\text { Papai pediu } \\
\text { pipoca }\end{array}$ & $\begin{array}{c}\text { O bebê } \\
\text { babou }\end{array}$ & Prontuário \\
\hline Média & 1,43 & 1,48 & 1,53 & 1,52 & 2,30 \\
\pm DP & 0,63 & 0,61 & 0,59 & 0,59 & 0,50 \\
\hline
\end{tabular}

Considerando o valor de corte de 1,5 para o julgamento perceptivo da nasalidade, $50(63 \%)$ dos indivíduos tiveram médias iguais ou abaixo de 1,5 e $29(37 \%)$ tiveram médias acima para o julgamento da palavra "papai". Para "bebê", $46(58 \%)$ tiveram médias iguais ou abaixo de 1,5 e 33 (42\%) médias acima deste valor. Para a frase "Papai pediu pipoca" 42 (53\%) tiveram médias iguais ou abaixo de 1,5 e $37(47 \%)$ tiveram médias acima deste valor. E finalmente para a frase "O bebê babou" 43 (54\%) dos indivíduos tiveram médias iguais ou abaixo de 1,5 e 36 (46\%) médias acima deste valor.

\section{2 Índices da Eficiência da Nasometria}

Para observarmos a eficiência da nasometria em confirmar os achados perceptivo-auditivos deste estudo foram obtidos os índices de sensibilidade e especificidade do nasômetro em confirmar presença e ausência da hipernasalidade. Os índices foram calculados individualmente para cada uma das duas palavras e das duas frases. Primeiramente foram incluídas todas 
as 79 amostras e depois estas foram subdivididas de acordo com a concordância entre as três julgadoras. No grupo A foram incluídas amostras onde houve total concordância entre as três (3 de 3), no grupo B as amostras para as quais duas julgadoras estiveram em concordância (2 de 3), e no grupo C as amostras para as quais houve total discordância entre as julgadoras.

\subsubsection{Amostra total}

Os resultados evidenciaram uma sensibilidade de $44 \%$ do nasômetro em identificar a hipernasalidade para a palavra "papai", de 23\% para a palavra "bebê", de $45 \%$ para a frase "Papai pediu pipoca" e de $30 \%$ para a frase o "O bebê babou". Quanto à especificidade, foram encontrados os resultados de $70 \%$ para a palavra "papai", $93 \%$ para a palavra "bebê", $81 \%$ para a frase "Papai pediu pipoca" e $92 \%$ para a frase "O bebê babou". Vide Tabela 6.

Tabela 6 - Resultados dos índices de sensibilidade e de especificidade do nasômetro para as duas palavras e duas frases

\begin{tabular}{lcc}
\hline \multicolumn{1}{c}{ Amostra de Fala } & $\begin{array}{c}\text { Sensibilidade (\%) } \\
\text { Valor de corte de 21\% }\end{array}$ & Especificidade (\%) \\
\hline Papai & 44 & 93 \\
Bebê & 23 & 81 \\
Papai pediu pipoca & 45 & 92 \\
O bebê babou & 30 & \\
\hline
\end{tabular}




\subsubsection{Amostra nos grupos $A, B$ e $C$}

Os resultados evidenciaram uma sensibilidade de $53 \%$ do nasômetro para a palavra "papai" do grupo A, de $25 \%$ para o grupo B e de $100 \%$ para o grupo C. Para a palavra "bebê, uma sensibilidade de $24 \%$ para o grupo $A$, de $15 \%$ para o grupo $B$ e de $100 \%$ para o grupo $C$. Para a frase "Papai pediu pipoca" uma sensibilidade de $48 \%$ para o Grupo A, de $38 \%$ para o grupo B e de $0 \%$ para o grupo C. Quanto à frase "O bebê babou", foi encontrada sensibilidade de $35 \%$ para o grupo $A$, de $23 \%$ para o grupo $B$ e de 0\% para o grupo $\mathrm{C}$.

Quanto à especificidade, para a palavra "papai" no grupo A esta foi de $71 \%$, no grupo B de $75 \%$ e no grupo C de $100 \%$. Para a palavra "bebê" no grupo A foi de $100 \%$, no grupo B de $90 \%$ e no grupo C de $100 \%$. Para a frase "Papai pediu pipoca" no grupo A foi de $87 \%$, no grupo B de $95 \%$ e no grupo C de $86 \%$. Para a frase "O bebê babou" no grupo A foi de $100 \%$, no grupo B de 90\% e no grupo C de 100\% (Vide Tabela 7). 
Tabela 7 - Resultados dos índices de sensibilidade e de especificidade do nasômetro na identificação da hipernasalidade para a amostra de fala separada conforme os grupos A, B e C

\begin{tabular}{|c|c|c|c|c|c|c|}
\hline \multirow{4}{*}{ Amostra } & \multirow{2}{*}{\multicolumn{3}{|c|}{$\begin{array}{c}\text { Sensibilidade (\%) } \\
\text { Valor de corte } 21 \%\end{array}$}} & \multirow{2}{*}{\multicolumn{3}{|c|}{ Especificidade (\%) }} \\
\hline & & & & & & \\
\hline & \multicolumn{3}{|c|}{ Grupos } & \multicolumn{3}{|c|}{ Grupos } \\
\hline & $A$ & $B$ & C & $A$ & $B$ & C \\
\hline Papai & 53 & 25 & 100 & 71 & 75 & 100 \\
\hline Bebê & 24 & 15 & 100 & 100 & 90 & 100 \\
\hline Papai pediu pipoca & 48 & 38 & 0 & 87 & 95 & 86 \\
\hline O bebê babou & 35 & 23 & 0 & 100 & 90 & 100 \\
\hline
\end{tabular}

\subsection{Nasometria}

\subsubsection{Amostra total}

Na Tabela 8 são apresentados os valores de nasalância (médias e desvios padrão) obtidos neste estudo durante a produção das palavras e das frases. Os valores médios de nasalância obtidos neste estudo foram: $24 \%$ ( \pm $12 \%)$ para a palavra "papai", $39 \%( \pm 28 \%)$ para bebê, $32 \%( \pm 16 \%)$ para "Papai pediu pipoca" e 39\% ( $\pm 17 \%)$ para "O bebê babou". 


\subsubsection{Amostra nos grupos A, B e C}

Ao subdividir as amostras de acordo com as concordâncias entre as julgadoras (grupo A, B e C) os valores de nasalância (médias e desvios padrão) obtidos foram: Para a palavra "papai” no grupo A de $39 \%$ ( $\pm 14 \%$ ), para o grupo B de $26 \%$ ( $\pm 11 \%$ ) e para o grupo C de $29 \%$ ( $\pm 13 \%$ ). Para a palavra "bebê": o grupo A teve 50\% ( $\pm 13 \%)$, o grupo B $46 \%( \pm 13 \%)$ e o grupo C $24 \%$ ( $\pm 14 \%)$. Para a frase "Papai pediu pipoca", o grupo A teve $52 \%( \pm 15 \%)$, o grupo B $54 \%( \pm 18 \%)$ e o grupo C $23 \%$ ( $\pm 15 \%)$. Para a frase "O bebê babou" o grupo A teve $51 \%$ ( $\pm 8 \%$ ), o grupo B $40 \%$ ( $\pm 14 \%)$ e Grupo C $23 \%( \pm 9 \%)$.

Tabela 8 - Médias e desvios padrão de nasalância, expressos em porcentagem, obtidos para os indivíduos da amostra durante a emissão das palavras e frases

\begin{tabular}{|c|c|c|c|c|}
\hline \multirow{3}{*}{$\begin{array}{l}\text { Amostras de } \\
\text { Fala }\end{array}$} & \multirow{3}{*}{$\begin{array}{c}\text { Todos } \\
\text { Índivíduos }\end{array}$} & \multicolumn{3}{|c|}{$\begin{array}{l}\text { Nasalância } \\
\text { Média (\%) } \pm \text { DP }\end{array}$} \\
\hline & & \multicolumn{3}{|c|}{ Grupos } \\
\hline & & A & B & C \\
\hline Papai & $24( \pm 12)$ & $39( \pm 14)$ & $26( \pm 11)$ & $29( \pm 13)$ \\
\hline Bebê & $39( \pm 28)$ & $50( \pm 13)$ & $46( \pm 13)$ & $24( \pm 14)$ \\
\hline $\begin{array}{l}\text { Papai pediu } \\
\text { pipoca }\end{array}$ & $32( \pm 16)$ & $52( \pm 15)$ & $54( \pm 18)$ & $23( \pm 15)$ \\
\hline O bebê babou & $39( \pm 17)$ & $51( \pm 8)$ & $40( \pm 14)$ & $23( \pm 9)$ \\
\hline
\end{tabular}




\subsection{Correlação entre nasalância e nasalidade de fala}

O Teste de Spearman revelou correlação estatisticamente significante entre os valores de nasalância e os de nasalidade para as amostras coletadas do prontuário para a palavra "papai" $(r=0,28 ; p=0,01)$ e frases "Papai pediu pipoca" ( $r=0,32 ; p=0,003)$ e "O bebê babou" $(r=0,30 ; p=$ $0,006)$, para a amostra de fala "bebê" $(r=0,13 ; p=0,23)$ não foi encontrado correlação estatisticamente significante.

Quanto à correlação entre os valores de nasalância e os de nasalidade de acordo com o julgamento perceptivo auditivo realizado pelas 3 julgadoras, os resultados evidenciaram correlação estatisticamente significante para as amostras "papai" ( $r=0,31 ; p=0,004)$, "bebê" $(r=0,26 ; p=0,01)$, "Papai pediu pipoca" ( $r=0,31 ; p=0,004)$ e "O bebê babou" $(r=0,37 ; p=$ 0,0007). Vide Tabela 9.

Para as amostras subdivididas entre os grupos $A, B$ e $C$, as correlações obtidas foram: para a palavra "papai", no Grupo A, a correlação foi de 0,26 ( $p=0,07)$, no Grupo B de - 0,01 ( $p=0,93)$ e no Grupo $C$ de 0,52 ( $p=$ 0,29). Para a palavra "bebê", no Grupo A, foi de 0,003 ( $p=0,45)$, no Grupo B de 0,09 $(p=0,60)$ e no Grupo $C$ de 0,09 $(p=0,80)$. Para a frase "Papai pediu pipoca”, no Grupo A foi de 0,35 ( $p=0,02)$, no Grupo B de 0,17 ( $p=0,3)$ e no Grupo C de 0,57 ( $p=0,16)$. Para a frase "O bebê babou, no Grupo A, foi de 0,58 ( $p=0,0002)$, no Grupo B de - 0,07 $(p=0,63)$ e no Grupo $C$ de $-0,42(p=$ 0,41). Das correlações acima, apenas obtidas para as frases "Papai pediu 
pipoca" e "O bebê babou" do grupo A, foram estatisticamente significantes. Vide tabelas 10, 11 e 12

Tabela 9 - Correlações ("r") entre julgamento perceptivo da nasalidade realizado pelas três julgadoras para as frases e palavras e medidas de nasalância para os 79 indivíduos para as mesmas frases e palavras. Também apresenta correlações ("r") entre julgamento perceptivo coletado do prontuário e medidas de nasalância obtidas para emissão das palavras e frases

\section{Correlação ("r")}

Julgamento Perceptivo-Auditivo da Nasalidade

\begin{tabular}{|c|c|c|c|c|c|}
\hline & Papai & Bebê & $\begin{array}{c}\text { Papai } \\
\text { pediu } \\
\text { pipoca }\end{array}$ & $\begin{array}{l}\text { O bebê } \\
\text { babou }\end{array}$ & Prontuário \\
\hline Papai & $0,31^{*}$ & & & & $0,28^{*}$ \\
\hline Bebê & & $0,26 *$ & & & 0,13 \\
\hline $\begin{array}{l}\text { Papai pediu } \\
\text { pipoca }\end{array}$ & & & $0,31^{*}$ & & $0,32^{*}$ \\
\hline $\begin{array}{l}\text { O bebê } \\
\text { babou }\end{array}$ & & & & $0,37^{*}$ & $0,3^{*}$ \\
\hline
\end{tabular}

$\mathrm{P} \leq 0,05^{*}$ 
Tabela 10 - Correlações ("r") entre julgamento perceptivo auditivo da nasalidade em normal e hipernasal e medidas de nasalância obtidas para as palavras e frases para o grupo A

\section{Correlação ("r")}

Julgamento Perceptivo-Auditivo da Nasalidade

\begin{tabular}{|c|c|c|c|c|}
\hline & Papai & Bebê & $\begin{array}{l}\text { Papai pediu } \\
\text { pipoca }\end{array}$ & $\begin{array}{l}\text { O bebê } \\
\text { babou }\end{array}$ \\
\hline Papai & 0,26 & & & \\
\hline Bebê & & 0,45 & & \\
\hline $\begin{array}{l}\text { Papai pediu } \\
\text { pipoca }\end{array}$ & & & $0,35^{*}$ & \\
\hline $\begin{array}{l}\text { O bebê } \\
\text { babou }\end{array}$ & & & & $0,58^{*}$ \\
\hline
\end{tabular}


Tabela 11 - Correlações ("r") entre julgamento perceptivo-auditivo da nasalidade em normal e hipernasal e medidas de nasalância obtidas para as palavras e frases para o grupo $B$

\section{Correlação ("r")}

Julgamento Perceptivo-Auditivo da Nasalidade

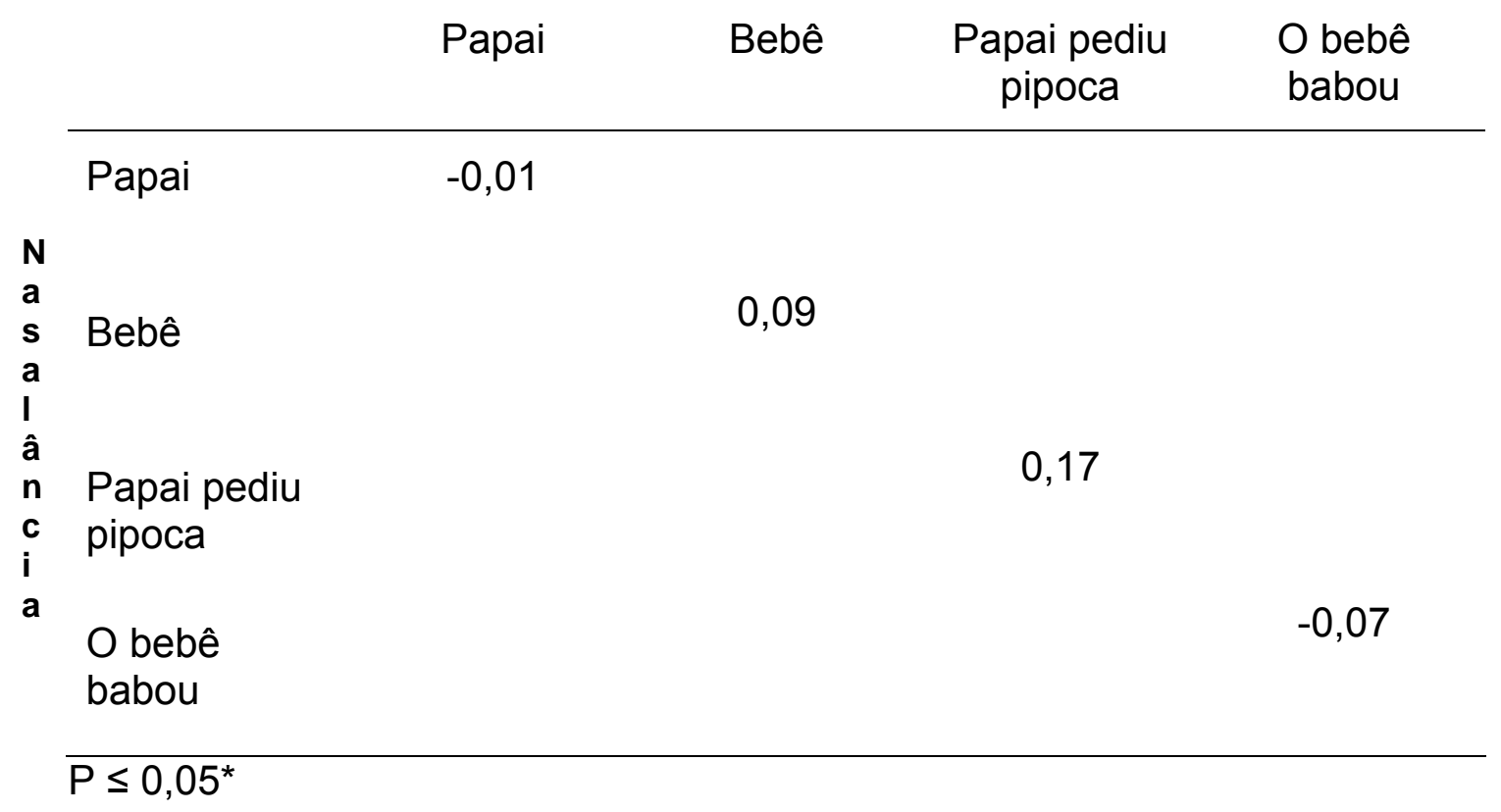


Tabela 12 - Correlações ("r") entre julgamento perceptivo auditivo da nasalidade em normal e hipernasal e medidas de nasalância obtidas para as palavras e frases para o grupo $\mathrm{C}$

\section{Correlação ("r")}

Julgamento Perceptivo-Auditivo da Nasalidade

\begin{tabular}{|c|c|c|c|c|}
\hline & Papai & Bebê & $\begin{array}{c}\text { Papai pediu } \\
\text { pipoca }\end{array}$ & $\begin{array}{l}\text { O bebê } \\
\text { babou }\end{array}$ \\
\hline Papai & 0,52 & & & \\
\hline Bebê & & 0,09 & & \\
\hline $\begin{array}{l}\text { Papai pediu } \\
\text { pipoca }\end{array}$ & & & 0,57 & \\
\hline $\begin{array}{l}\text { O bebê } \\
\text { babou }\end{array}$ & & & & $-0,42$ \\
\hline
\end{tabular}



6 - DISCUSSÃO 



\section{DISCUSSÃO}

O objetivo deste estudo foi o de estabelecer a correlação entre medidas de nasalância e julgamento perceptivo-auditivo da nasalidade da fala de crianças com fissura unilateral de lábio e palato, falantes do Português Brasileiro. O uso de medidas instrumentais objetivas, padronizadas e normatizadas para avaliar a função velofaríngea tem sido recomendado com freqüência na literatura, com o intuito de auxiliar e complementar a avaliação clínica (DALSTON, 1991, MOON, 1993). Por este motivo, a análise instrumental acústica do sinal de fala foi desenvolvida como meio de corroborar os testes perceptivos da ressonância de fala. De um modo geral, muitos autores constataram que a correspondência entre nasometria e julgamento perceptivo-auditivo não é exata, embora a nasometria tenha sido efetiva na detecção de pacientes que tiveram parecer clínico de hipernasalidade importante. (DALSTON et al.,1991, HARDIN et al., 1992, NELLIS et al., 1992, DALSTON; SEAVER 1992, DALSTON et al., 1993, DUTKA 1996, WATTERSON et al., 1996, 1998, KEUNING et al., 2002, LEWIS, 2003 e HISCHERBEG, 2005).

Em nosso estudo, quando correlacionamos os valores das medidas de nasalância com os do julgamento perceptivo-auditivo, os resultados evidenciaram que apesar de estatisticamente significantes a correlação foi baixa (média $=0,25$ ). Estes resultados corroboram com os achados de NELLIS et al. (1992) que também encontraram baixa correlação entre estas duas variáveis, discordando de DALSTON; SEAVER (1992), DALSTON et al., 
(1993), DUTKA, (1996), WATTERSON, (1998), HIRSCHBERG et al., (2005), que encontraram em seus estudos uma alta correlação, e de WATTERSON et al., (1996), KEUNING et al., (2002), LEWIS et al., (2003), que encontraram uma correlação moderada.

A baixa correlação em nosso estudo entre o julgamento perceptivoauditivo realizado pelas julgadoras e a nasalância, poderia estar associada ao tamanho do estímulo usado - duas palavras e duas frases curtas - o que pode ter dificultado a percepção da hipernasalidade pelas julgadoras. Segundo WATTERSON et. al. (1999), estímulos de fala com seis sílabas poderiam ser suficientes para obter medidas de nasalância válidas em crianças. Por outro lado, estímulos com menos de seis sílabas poderiam limitar a obtenção da medida de nasalância devido à possível influência do número limitado de fonemas. Ainda segundo os autores, estímulos de apenas duas sílabas, como os do presente estudo, não seriam suficientes para obtenção confiável da medida de nasalância, e por isso, não deveriam ser utilizados. Os resultados de nosso estudo nos levam a concordar com tal afirmação, haja vista que as maiores correlações foram obtidas para as frases.

Ainda refletindo sobre o contexto fonêmico do estímulo de fala utilizado para obtenção da nasalância, vale mencionar o estudo de WATTERSON et al. (1996) que compararam as medidas de nasalância e os julgamentos perceptivos de nasalidade em amostras de fala constituídas por fonemas de alta e de baixa pressão, em indivíduos normais e indivíduos com hipernasalidade. Os resultados demonstraram que não houve diferença 
estatisticamente significante entre os estímulos de alta e de baixa pressão, tanto para as medidas de nasalância como para os julgamentos perceptivos de nasalidade.

Em outros estudos como os realizados por DALSTON; SEAVER (1992), DALSTON et al., (1993), WATTERSON, (1998), HIRSCHBERG et al. (2005) nos quais encontraram alta correlação entre nasalidade e nasalância e, nos estudos realizados por WATTERSON et al., (1996), KEUNING et al., (2002), LEWIS et al., (2003) encontraram moderada correlação, foram utilizados em sua maioria textos. Uma exceção foi o estudo de LEWIS et al. (2003), que ao utilizar uma única frase, encontraram uma correlação de baixa à moderada. De acordo com KEUNING et al. (2002), a alta correlação entre nasalância e julgamento da nasalidade reportada por DALSTON et al. (1993), por exemplo, poderia ser explicada pelo fato da hipernasalidade dos pacientes estudados por DALSTON et al. ter variado de grau leve a severo. Este argumento leva-nos a pensar que uma possível explicação quanto à baixa correlação entre nasalância e nasalidade encontrada em nosso estudo, se deva ao fato que a maioria de nossas crianças apresentou hipernasalidade leve ou ausência de hipernasalidade, de acordo com o julgamento perceptivo das três julgadoras.

Quando este estudo foi desenhado, já prevíamos que as julgadoras pudessem ter dificuldade de julgar as amostras de fala pelo fato de tais amostras constituírem-se de palavras isoladas e frases curtas. Para minimizar esta possível dificuldade, e para evitar que as mesmas tivessem que parar a 
gravação e voltar a fita com o objetivo de escutá-la novamente, editamos a gravação de cada estímulo por três vezes consecutivas. Esta medida, apesar de facilitar o julgamento da nasalidade, já que a julgadora tinha mais tempo para julgar a amostra, parece não ter sido suficiente para melhorar a correlação com a nasalância.

Os nossos achados discordam dos achados de DUTKA (1996) que utilizando dois estímulos iguais aos do presente estudo - "bebê" e "O bebê babou" - para correlacionar nasalidade e nasalância encontrou alta correlação. Acreditamos que a alta correlação se deva ao fato de que no estudo da autora a amostra era composta por adultos e crianças com diferentes graus de hipernasalidade, variando de grau leve ao grau severo.

Nosso estudo ainda verificou a correlação entre nasalidade e nasalância no grupo de amostras para o qual houve total concordância entre as julgadoras (grupo A), no grupo para o qual houve concordância entre duas das três julgadoras (grupo B), e no grupo para o qual não houve concordância entre as três julgadoras (grupo C). As correlações obtidas para todos os grupos foram baixas. No entanto, tais correlações foram um pouco melhores para o grupo A, cuja significância estatística foi obtida apenas para a emissão das frases "Papai pediu pipoca" $(r=0,38)$ e "O bebê babou" $(r=0,53)$. Nossos resultados confirmam os achados de DUTKA (1996) que também dividiu seus resultados em grupos de acordo com a concordância entre seus julgadores encontrando que a relação entre nasalância e nasalidade melhora conforme aumenta a concordância entre os julgadores. 
Ao compararmos o resultado dos julgamentos obtidos a partir das gravações com os pré-existentes no prontuário, verificamos que mais da metade das julgadoras julgou como normal as amostras produzidas pelas crianças que já haviam sido identificadas como hipernasais. Uma hipótese seria o fato de que o avaliador que julgou a nasalidade de fala e anotou sua classificação no prontuário do paciente, o fez baseado em amostra de fala espontânea. Além disso, é provável que alguns pacientes tenham apresentado ronco nasal ou emissão de ar nasal audível durante a avaliação o que poderia levar o avaliador a julgar presença de hipernasalidade em maior ou menor grau. Um outro fator a ser considerado é que esta avaliação não foi feita por meio de gravação e o avaliador também pode ter levado em consideração outros aspectos da fala que poderiam estar alterados, como por exemplo, a presença de articulações compensatórias, ou até mesmo a presença de mímica facial. Um último fator a ser considerado é que provavelmente os 79 pacientes de nossa amostra tenham sido avaliados por, pelo menos, 5 julgadores diferentes que certamente levaram em consideração critérios diferentes para julgar a nasalidade de fala dos pacientes.

Seguindo a hipótese de que nossas três julgadoras foram instruídas a julgar hipernasalidade (quando presente) em leve, moderada e severa utilizando estímulos curtos com predomínio das mesmas consoantes, as mesmas o tenham feito com dificuldade, haja vista que a ressonância dos pacientes variou entre nasalidade normal e hipernasalidade leve. Se, ao contrário tivessem sido instruídas a julgar apenas presença ou ausência de hipernasalidade, talvez as correlações entre nasalidade e nasalância fossem 
melhores. Neste sentido, DALSTON (1991) reporta que uma alta correlação entre nasalância e nasalidade pode ser alcançada quando a amostra é constituída por indivíduos com hipernasalidade de moderada a severa.

De forma a validar o uso do nasômetro como instrumento confiável e válido para confirmar presença ou ausência de hipernasalidade, foram calculados os valores de sensibilidade e de especificidade. Os resultados encontrados em nosso estudo favoreceram de um modo geral a especificidade. Estes resultados sugerem que o valor de corte utilizado (21\%) pode não ter sido o mais adequado para esta amostra. Porém se tivéssemos considerado o julgamento perceptivo-auditivo do prontuário para realizar este cálculo, poderíamos ter encontrado um maior valor de sensibilidade, haja vista que todos os indivíduos haviam sido previamente julgados como hipernasais. Nossos achados concordam com os achados de DALSTON et al. (1991), HARDIN et al. (1992), DALSTON et al. (1993), WATTERSON et al. (1998) nos quais o valor de corte favoreceu a especificidade, apesar de terem utilizado valores de corte diferentes do nosso. Entretanto, nossos achados discordam de DUTKA (1996), a qual, utilizando um valor de corte de $27 \%$ para a palavra e $21 \%$ para a frase, encontrou resultados que favoreceram a sensibilidade. Esta diferença encontrada entre todos os estudos citados pode ser devido aos diferentes valores de nasalância encontrados para cada população. Segundo HARDIN et al. (1992), considerar um único valor de corte para todos os pacientes pode ser inapropriado, devido às diferenças dialetais de cada região. Desta forma, podemos considerar que ajustes no valor de corte, afetam tanto a sensibilidade quanto à especificidade. A escolha entre priorizar a sensibilidade 
(e diminuir o número de falsos negativos) ou priorizar a especificidade (e diminuir o número de falsos positivos) deve ser baseada na necessidade clínica da população em questão. 



\section{7 - CONCLUSÃO}





\section{CONCLUSÃO}

Concluímos com nosso estudo que a correlação entre nasalância e nasalidade em uma amostra de crianças com ressonância de fala variando entre normal e hipernasal leve é baixa, principalmente quando se utiliza estímulos de fala curtos com predomínio de uma única consoante.

Sugerimos que estudos futuros que tenham como objetivo correlacionar nasalância e nasalidade utilizem estímulos de fala mais longos, com diferentes contextos fonéticos. Além disso, o controle de variáveis que possam influenciar no julgamento perceptivo auditivo da nasalidade como ronco nasal, emissão de ar nasal, presença de articulações compensatórias deveriam ser consideradas. Além disso, sugerimos que o valor de corte seja estabelecido para cada amostra de indivíduos, pois o que pode ser bom para uma amostra, pode não ser bom para outra. 



\section{REFERÊNCIAS}





\section{REFERÊNCIAS}

BAKEN, R. J. Clinical measurement of speech and voice. Boston: College-Hill. Press, $1997.518 p$.

BZOCH, K. Communicative disorders: related to cleft lip and palate. 5a ed. Austin: Pro. Ed, 2004. 866 pag.

DALSTON, R. M.; WARREN, D. W. Comparison of tonar II, pressure flow and listener judgements of hypernasality in the assessment of velopharyngeal function. Cleft palate J, Pittsburg, v. 23, n. 2, p.108-115, Apr. 1986.

DALSTON, R. M.; WARREN, D. W.;DALSTON, E. T. Use of nasometry as a diagnostic tool for identifying patients with velopharyngeal impairment. Cleft Palate Craniofac J, Pittsburg, v. 28, n. 2, p. 184-189, Apr.1991.

DALSTON, R. M.; SEAVER, E. J. Relative values of various standardized passages in the nasometric assesment of patients with velopharyngeal impairment. Cleft Palate Craniofac J, Pittsburg, v. 29, n.1, p. 17-21, Jan.1992.

DALSTON, R. M.; GONZALES-LANDA, G. Nasometric sensitivity and specificity: a croos-dialect and croos-culture study. Cleft Palate Craniofacial J, Pittsburg, v. 30, n. 3, p. 285-291, May 1993.

DI NINNO, C. Q. M. S. et al. Determinação dos valores de nasalância para falantes normais do português brasileiro. Pró-fono, São Paulo, v. 13, n. 1, p. 71-77, 2001.

DUTKA, J. C. R. Evaluation of a modified procedure for use of the Kay Elemetrics'Nasometer for nasometric assessment of children younger than five years of age. Unpublished master's thesis. University of Florida: Gainesville.1992.

DUTKA, J. C. R. Relationship between perceptual ratings of nasality during cul-de-sac testing and nasalance escores. 1996. 125p. Thesis (Doctor) University of Florida, Gainesville, FL,

FLEISS, J. L. Statistical methods for rates and proportions. New York: Jonh Wiley \& Sons, 1973. 
FLETCHER, S. G. Measurement of nasality with tonar. Cleft Palate

Craniofacial J, Pittsburg, v. 7, p. 610-621, Apr.1970.

FLETCHER, S. G. "Nasalance" vs. listener judgments of nasality. Cleft Palate J, Pittsburg, v. 13, p. 31-44, Jan.1976.

FLETCHER, S. G. Diagnosing speech disorders from cleft palate. New York, Grunne e Stratton, 1978.

FLETCHER, S. G.; ADAMS, L. E.; McCUTCHEON, M. J. Cleft palate speech assessment through oral-nasal acoustic measures. In: BZOCH, K. R.(Ed) Comunication disorders related to cleft lip and palate. Boston: College-Hill Press, 1989.

GENARO, K. F.; YAMASHITA, R. P.; TRINDADE, I. E. K. Avaliação clínica e instrumental na fissura labiopalatina. In: FERREIRA, L. P.; BEFI-LOPES, D. M.; LIMONGI, S. C. O., Tratado de fonoaudiologia. São Paulo: Rocca, 2004, cap. 6 p. $456-477$.

HARDIN, M. A. et al. Correspondence between nasalance scores and listener judgements of hipernasality and hiponasality. Cleft palate Craniofacial J, Pittsburg, v. 29, p. 346-351, 1992.

HIRSCHBERG, J. et al. Adaptation of nasometry to hungarian language and experience with its clinical aplication. Int J Pediatr Otorhinolaryngol, Amsterdam, v. 70, n. 5, p.785-798, May. 2006.

JEKEL, J. F.; JAMES, F. KATZ, D. L.; ELMORE, J. G. Epidemiologia, bioestatística e medicina preventiva. $2^{\mathrm{a}}$ ed. Porto Alegre: Artmed, 2005, 432p.

KAY ELEMETRICS CORPORATION. Instruction manual of Nasometer ${ }^{\mathrm{TM}}$ model 6200-2 IBM® PC version. Pine Brook: Kay, 1992, 96p.

KAY ELEMETRICS CORPORATION. Nasometer's instructional manual model 6200. Pine Brook, NJ, 07058, 1982.

KENT, R. D. Hearing and believing: some limits to the auditory-perceptual assessment of speech and voice. Am J Speech Lang Pathol, Rockville, v. 5, p. 7-23, 1996. 
KEUNING, K. H. D. M. et al. The correlation between nasalance and a differentiated perceptual rating of speech in Dutch patients with velopharyngeal insufficiency. Cleft Palate Craniofac J, Pittsburg, v. 39, n. 3, p. 277-283, May 2002.

KUMMER, A. W. Velopharyngeal dysfunction (VPD) and resonance disorders. In: KUMMER, A. W. Cleft palate and craniofacial anomalies: effects on speech and resonance. San Diego: Singular Learning, 2001. p. 145-176.

LANDIS, J. R.; KOCH, G. G. The measurement of observer agreement for categorical data. Biometrics, Washington, v. 33, p. 159-174, Mar. 1977.

LEWIS, K. E; WATTERSON, T. L.; HOUGHTON, S. The influence of listener experience and academic training on ratings of nasality. J Commun Disord, Amsterdam, v. 36, p. 49-58, 2003.

LIMA, A. M. Perfil espectrográfico e nasométrico da vogal /a/ em diferentes condições de abertura velofaríngea. 2006. Dissertação (Mestrado) - Escola de Engenharia de São Carlos, Universidade de São Paulo, São Carlos, 2006.

MOON, J. B. Evaluation of velopharyngeal function. In: MOLLER, K.T.; STARR, C.D. (Ed). Cleft palate interdisciplinary issues and treatment: for clinicians by clinicians. Austin: Pro-ed, 1993.

MURRAY, J. C. Gene/environment causes of cleft lip na/or palate. Clin. Genet, Copenhagen, v. 61, n. 4, p. 248 - 256, Apr. 2002.

NELLIS, J. L.; NEIMAN, G. S.; LEHMAN, J. A. Comparison of nasometer and judments of nasality in the assesment of velopaharyngeal functionafter pharyngeal flap surgery. Cleft palate craniofac J, Pittsburg, v.29, n.2, p.157163, March 1992.

PEGORARO-KROOK, M. I. Avaliação da fala de pacientes que apresentam inadequação velofaríngea e que utilizam prótese de palato. São Paulo, 1995. 130p. Tese (Doutorado) - Escola Paulista de Medicina.

PEGORARO-KROOK, M. I. Efeito da descongestão nasal nas medidas de nasalância. Tese de Livre-Docência, Departamento de Fonoaudiologia da Faculdade de Odontologia de Bauru, Universidade de São Paulo, 2004. 
PERTERSON-FALZONE, S. J.; HARDIN-JONES, M.A.; KARNEL, M.P. Cleft Palate Speech. $3^{\text {rd }}$ ed.Saint .Louis: Mosby, 2001. 195 p.

RIBEIRO, A. C. et al. Valores normativos de nasalância para identificação de desvios de nasalidade. In: ENCONTRO CIÊNTÍFICO DA PÓS - GRADUAÇÃO DO HRAC-USP, 3.,1999, Bauru, Anais. Bauru: Hospital de Reabilitação de Anomalias Craniofaciais, Universidade de São Paulo, 1999, p.32-33.

ROCHET, A. P. et al. Caracteristics of nasalance in speakers of western canadian English an French. Revue D'Orthophonie et D'Audiologie, v. 22, n. 2, p. 94-102, 1998.

SONY. Sony Sound Forge. Madison: Sony, 2003. Disponível em: <http://www.sonymediasoftware.com>. Acesso em 19 Marc. 2007.

SUGUIMOTO, M. L. C. P.; PEGORARO-KROOK, M. I. Avaliação nasométrica em adultos normais falantes do Português Brasileiro. Pró-fono, São Paulo, .v. 7, n. 2, set.1995.

TRINDADE, I. E. K.; TRINDADE JUNIOR, A.S. Avaliação funcional da inadequação velofaríngea. In: CARREIRÃO, S.; LESSA, S., ZANINI, A.S. (Ed.). Tratamento das fissuras labiopalatinas. 2. ed. Rio de Janeiro: Revinter, 1996. cap. 26, p. 223-235.

TRINDADE, I. E. K.; GENARO, K. F.; DALSTON, R. M. Nasalance Score of Normal Brazilian Portuguese Speakers. Braz J. of Dysmorphology SpeechHear Disord, São Paulo, v. 1, p. 23-34. 1997.

TROST-CARDAMONE, J. E. Diagnosis of specific cleft speech error patterns for planning therapy or physical management needs. In: BZOCH K. R. Communicative disorders related to cleft palate speech. $4^{\text {th }} \mathrm{ed}$. Boston: Little, Brown, 2004. p137-173.

VAN LIERD, K. M. et al. Effect of cleft type on overall speech inteligibility and ressonance., Folia Phoniatr Logop, Basel, v. 54, p. 158-168, 2002.

VAN LIERDE, K. M. et al. Nasometric values for normal nasal ressonance in the speech of young flemish adults. Cleft Palate Craniofacial J, Pittsburg, v. 38, n. 2, p. 112-118, 2001. 
VAN LIERDE, K. M.; et al. Age-related patterns of nasal ressonance in normal flemish children and young adults. Scand J Plast Reconstr Surg Hand Surg, Stockholm, v. 37, p. 344-350, 2003.

WATTERSON, T.; McFARLANE, S. C. The Relationship between nasalance and nasality in children with cleft palate. J Commun Disord, Amsterdam, v. 26, p. 13-28, 1993

WATERSON, T.; HINTON, J.; McFARLANE, S. Novel stimuli for obtaining nasalance measures from young children. Cleft Palate Craniofac J, Pittsburg, v. 33, n.1, p. 67-73, 1996.

WATERSON ,T; LEWIS, K.E.;DEUTSCH, C. Nasalance and nasality in low pressure and high pressure speech. Cleft Palate Craniofac J, Pittsburg, v.35, n. 4, p. 293 - 298, 1998.

WATTERSON, T.; LEWIS K.E.; FOLEY-HOMAN, N. Effect of stimulus lengh on nasalance scores. Cleft Palate Craniofac J, Pittsburg, v. 36, n. 3, p. 243247,1999 . 



\section{ABSTRACT}

\section{Nasalance measures in children with cleft lip and palate and its correlation with auditory-perceptual ratings of nasality.}

The objective of the present study was to correlate nasalance scores and speech nasality of 79 operated unilateral cleft lip and palate children (males and females), with ages ranging from 4 to 9 years (mean 6.5 years), all speakers of Brazilian Portuguese. All children had already undergone perceptual evaluation of speech nasality, nasometric evaluation, and audio recordings, which took place at the (HRAC-USP). Out of the pré-existed audiorecordings it have been selected to this study the words: "papai" and "bebê", and the phrases "Papai pediu pipoca" and "O bebê babou". In spite of the indication that all children had already been judged to present mild, moderate or severe hypernasal speech, speech stimulate which have been audio recorded simultaneously to nasometry were judged again by 3 other experienced speech pathologists. The three speech pathologists were instructed to judge speech nasality. Each speech sample was judged individually by means of a 4 point scale $(1=$ normal nasality, 2 = mild hypernasality, $3=$ moderate hypernasality, and $4=$ severe hypernasality). The scores given by the three speech pathologist for the words and phrases varied from 1.0 to 3.3. Considering the cutoff value of 1.5 for perceptual judgements of nasality, $50(63 \%)$ of the children were judged to present means equal 1.5 or below, and $29(37 \%)$ presented means above 1.5 for the word "papai". For the word "bebê", $46(58 \%)$ presented means equal 1.5 or below, and $33(42 \%)$, means above this value. For "Papai pediu pipoca", 42 $(53 \%)$ presented means equal 1.5 or below, and $37(47 \%)$ means above this value. For the phrase "O bebê babou", $43(54 \%)$ of the children presented with means equal 1.5 or below, and $36(46 \%)$ means above this value. The obtained results have also shown that the sensibility of the nasometer to identify hypernasality for the word "papai" was $44 \%, 23 \%$ for "bebê", $45 \%$ for "Papai pediu pipoca", and $30 \%$ for "O bebê babou". With regard to specificity, the results have shown $70 \%$ for the word "papai", $93 \%$ for "bebê", $81 \%$ for "Papai pediu pipoca", and $92 \%$ for "O bebê babou". The nasalance scores obtained in the present study were $24 \%$ for the word "papai", $39 \%$ for "bebê, $32 \%$ for "Papai pediu pipoca"', and $39 \%$ for "O bebê babou". We have concluded in this study that the correlation between nasalance and nasality in a sample of children presenting with speech resonance ranging between normal and mild hypernasality is low, specially when using short speech stimulae with the predominance of only one consonant. We suggest for future studies which aims to correlate nasalance and nasality be designed to use longer speech stimulae with different phonemic context. Besides that the control of possible variables which might influence perceptual judgements of nasality, such as presence of snort, nasal air emission, compensatory articulations should also be considered. We also suggest that the cutoff value for nasalance scores should be established for each sample of individuals, because what might be good for one sample, might not be for another.

KEY WORDS: cleft lip and palate, nasometry, auditory-perceptual judgment, hypernasality, speech resonance. 
